(C) 2019 Elsevier B.V. This manuscript version is made available under the CC-BY-NC-ND 4.0

\title{
Attention to Online Channels across the Path to Purchase:
}

\section{An Eye-Tracking Study}

Currently, consumers display what is known as omnichannel behavior, that is, the combined use of digital and physical channels providing them with multiple points of contact with firms. We combine the Stimulus-OrganismResponse model and the visual attention theory to study how customers' attention to digital channels varies across different purchasing tasks. We use eye-tracking techniques to observe attention in an experimental setting. The experimental design is composed of four purchasing tasks in four different product categories and measures the attention to the website and time spent on each task in addition to several control variables. The results show that shoppers attend to more areas of the website for purposes of website exploration than for performing purchase tasks. The most complex and time-consuming task for shoppers is the assessment of purchase options. The actual purchase and postpurchase tasks require less time and the inspection of fewer areas of interest. Personal involvement also plays a role in determining these patterns by increasing attention to the product area.

\section{Keywords}

Customer journey, purchase task, eye-tracking, channel perception, experimental design

\section{Introduction}

Analysis of the web customer's experience is an increasingly important area of research, not only because online retailing is currently a basic feature of all sectors (in 2017, online sales worldwide grew by $24.8 \%$ with respect to the previous year and comprised $10.2 \%$ of total retail sales worldwide (Statista, 2019)), but because these marketing channels have also gained importance as platforms for communication and distribution of services in an omnichannel environment (Verhoef et al., 2015). 
Consumer behavior in such a context is becoming ever more complex, as customers use combinations of these multiple channels and points of contact with firms along what is known as the customer journey to satisfy their needs and purchase requirements (Cassab and MacLachlan, 2009). A recent study involving a sample of 46,000 customers of a US retailer revealed that the vast majority (73\%) use a combination of physical and digital channels to do their shopping (Sopadjieva et al., 2017). Another study conducted in 2016 in the Spanish fast fashion sector showed that $60 \%$ of the customers were omnichannel shoppers (Chocarro et al., 2018).

Analyzing this multitude of points of contact between consumers and companies and the information flow generated in these interactions is a top priority both for business and academia. For example, the Marketing Science Institute points to the omnichannel phenomenon as one of the five marketing research priorities for the 2018-2020 period (Marketing Science Institute, 2018). Another important rising trend is the data flow from the Internet of Things (IoT), which interconnects people and objects anytime and anyplace with anything and anyone, using any path/network and any service (Wang et al., 2017). Therefore, the understanding of how today's consumer purchasing process evolves is essential for firms confronted with the design and management of these channels and points of contact (Beck and Rygl, 2015).

There are various discernible stages along the customer's journey through the purchasing process (Neslin et al., 2006): the prepurchase stage in which the consumer seeks and analyzes information prior to making a choice; the purchase stage in which the consumer makes the purchase; and the postpurchase stages, which include the use of customer services or customer review sites. Consumers' objectives change and vary in complexity as they progress through the different stages (Neslin et al., 2006; Verhoef et al., 2007). 
As they experience these stages fulfilling their objectives, consumers respond to the stimuli presented by the various channels, in other words, the so-called "atmospherics" (Kotler, 1973). The literature has used the term atmospherics to refer to the elements of the shopping environment that affect the consumer's purchasing process. Turley and Milliman (2000) offer a review of over 60 studies linking consumer behavior to point-of-sale atmospherics, including a variety of factors relating to the inner and outer store appearance, store design, atmosphere, layout, colors and sounds.

A prerequirement of any response is attention to the stimulus, which is a largely unconscious process (Kellogg, 1980; Sandage, 1946). Consumer attention is a scarce resource for which companies compete (Davenport and Beck, 2001). A major part of retailers' work is spent attempting to garner the customer's attention (Puccinelli et al., 2009). Research regarding the role of the attentional processes has been mainly concentrated on advertising (Belanche et al., 2017; Brasel and Gips, 2008; Drèze and Hussherr, 2003; Lee and Ahn, 2012; Pieters and Wedel, 2004; Rayner et al., 2001; Wedel and Pieters, 2000) and, to a minor extent, on website processing due to its later introduction (Hasan, 2016; Leuthold et al., 2011; Lindgaard et al., 2006; Liu et al., 2011; Richard, 2005, among others; Shi et al., 2013; Velásquez, 2013; Wang et al., 2014). There are studies that combine exposure to advertisements during the search in an online store (Ahn et al., 2018).

The prior research suggested that consumers will act differently when they are considering different tasks (Hong et al., 2004). In the online environment, when users visit a website, their attention to the stimuli varies according to what they are aiming to achieve, which depends, in turn, on which stage of the purchasing process they are engaged in (Rowley, 2000). Leuthold et al. (2011) show how customers' web navigation strategies vary according to the complexity of 
the task; therefore, retailers may need to tailor their web designs to match different customer tasks. The same study reveals that the more time the task requires, the greater is the cognitive load (Leuthold et al., 2011); this depends on the complexity of the task.

A scheme presented by Huizingh (2000) shows that website stimuli can be separated into different levels. At level one, the stimuli are split into two groups: design features and content features. At level two, the content features include commercial information, product information, transaction information, and other content, such as entertainment elements of less direct relevance on commercial websites. This information is presented on various sections of the website or so-called areas of interest (AOIs); the main ones are the header, the product area and the navigation menu.

Thus, the objective of this paper is to examine precisely how the consumer attention process in the different AOIs on a website varies according to which of the three stages of the purchasing process the consumer is engaged in. Specifically, our objectives are to:

1. Analyze the effect of the stage in the purchasing process on the time taken to complete the task. Does task completion time vary with each stage?

2. Analyze the effect of the stage in the purchasing process on the AOIs visited. Do the AOIs visited vary with each stage?

3. Analyze the effect of the stage in the purchasing process on the exploration pattern. Does the exploration pattern vary with each stage? 
This paper contributes to the literature with a novel analysis of variations in attention processes in digital environments in the three stages of the purchasing process using observational techniques and eye-tracking methods. The customer's experience along the customer journey is internal and subjective (Meyer and Schwager, 2007) and therefore difficult to measure through declarative responses, as in a questionnaire. This paper adopts eye-tracking as an attention-measuring tool. Eye tracking is described by Lemon and Verhoef (2016) as a useful means to explore more deeply the experiences of the customer throughout the customer journey. The use of eye-tracking for attention measurement is not new (Wedel, 2015). However, the analysis of observational data alone could lead us to overlook relationships with other key variables such as the effect of the online purchasing experience or category involvement.

Therefore, another contribution of this paper is to investigate the attention process by performing a joint analysis of eye-tracker data and declarative feedback from a questionnaire.

In the following section, we provide a conceptual framework for the study and present the propositions. Section 3 contains the research design, and section 4 contains the results, discussion and modeling process. Our conclusions are presented in the final section.

\section{Conceptual framework and propositions}

The stimulus-organism-response (S-O-R) paradigm from the field of environmental psychology posits that the various aspects of the environment act as stimuli (S) that affect the internal states $(\mathrm{O})$ of people, which, in turn, drive their behavioral responses $(\mathrm{R})$ (Lin et al., 2017). External Stimuli (S) involve different aspects from environmental factors and conditions, which can be divided into social, design, and ambient factors (Herrando et al., 2018). The term "organisms" $(\mathrm{O})$ is used to refer to the inner states of perceptions, feelings, and thinking 
exercises (Luqman et al., 2017). These states result in specific behavioral responses (R): the approach or avoidance behaviors of the consumer (Ettis, 2017). The S-O-R framework was proposed by Mehrabian and Russell (1974) and later applied to the retail context by Rossiter and Donovan (1982) and to online retailing by Eroglu et al. (2001).

In a different research stream, attention is a cognitive phenomenon that has been studied since the late XIX century and can be conceived as the means of processing the vast amount of information with which people are confronted, prioritizing some aspects of information while ignoring others (Näätänen, 2018). These attentional processes include visual attention, auditory attention, spatial attention and phenomena as selective attention, divided attention and distraction (Pashler, 2016).

Attentional processes related to the visual stimuli are especially relevant. As Wedel and Pieters (2008) note “...visual attention is important in its own right. First, ... visual attention is not only a gate, but ..., a key coordinating mechanism that serves to maintain information processing and other goals over time". The visual marketing attention theory (Wedel and Pieters, 2008) differentiates between bottom-up and top-down sources as determining factors that drive the attentional processes related to the visual marketing stimuli. Bottom-up factors that affect the attention result from the physical features of the visual stimuli to which the consumers are exposed. In contrast, top-down factors are related to individuals' unique aspects such as expectations, objectives and emotions. These factors are personal characteristics affecting the attentional process. The attentional process is linked to the so-called downstream effects: learning, preference formation and choice and eventually, sales.

The model of visual attention is closely related to the S-O-R framework. In fact, the so-called bottom-up factors in the visual marketing theory by Wedel and Pieters (2008) are equivalent to 
the term External Stimuli in the S-O-R framework and the term "atmospherics" by Eroglu et al. (2001). Moreover, the bottom-up factors are a more general term for the two moderators included in the S-O-R model developed by Eroglu (2001). The downstream effects in the theory of attention to visual marketing can be divided into, first, inner states included in the Organism term, and second, Response states.

In this research, we combined both frameworks in a more integrative model of response to atmospherics in online retailing. This model is presented in Figure 1:

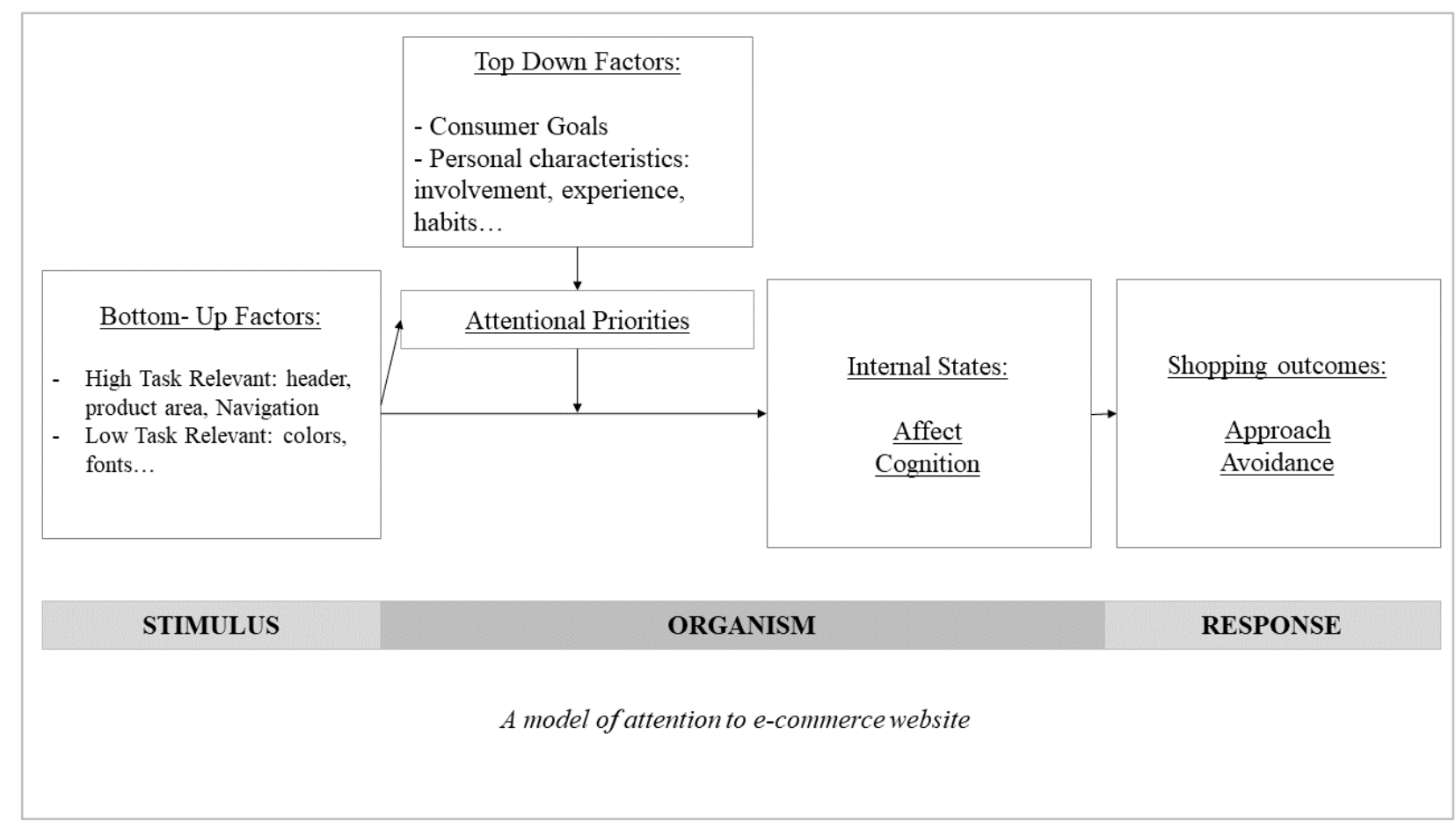

Figure 1. Conceptual Framework.

In this model, the online shopping environment includes all the features of a given website. We can use the term "atmospherics" as a general term for bottom-up factors. Web atmospherics are "...the conscious designing of Web environments to create positive affect and/or cognitions in surfers in order to develop positive consumer responses" (Dailey, 2004). The model designed 
by Eroglu et al. (2001) classifies stimuli as task-relevant (product descriptions, prices, service conditions, and product images) or task-irrelevant (colors, outlines, fonts, and animations).

These features are able to capture a subject's attention even in a nonactively searching condition of the consumer (Wolfe, 1998). The research devoted to attention to bottom-up factors using the visual marketing attention theory has also been oriented to study navigation strategies (Drèze and Hussherr, 2003), appearance evaluation (Lindgaard et al., 2006; Manippa et al., 2019), product presentation (Shi et al., 2013), web atmospherics (Dailey, 2004; Richard, 2005) and visual vs text information (Cortiñas, Monica and Chocarro, Raquel and Villanueva, Arantxa, 2019). Moreover, it is likely that the attentional process in the online framework varies as a function of the product category in the store (Leuthold et al., 2011; Shi et al., 2013; Wang et al., 2014).

In this framework, a subject's top-down factors are factors such as the engagement with the product online, the acquaintance of the brand, the purchase task (Rayner et al., 2001), or the experience (Samant and Seo, 2016). Studies have shown that other personal characteristics such as gender and age can also influence attention to websites (Huang, 2018, p. @ Castilla2016).

In this paper, we focus on two factors and their relationship: a top-down factor, namely, the purchase task, and a bottom-up factor, that is, the information in the different AOIs of the website.

Customers' online behavior varies according to the task they are engaged in. Neslin et al. (2006) present a conceptual framework accommodating these perspectives and including three distinct main stages (search, purchase and after-sales) through which the consumer progresses after initial need-recognition and during which he or she develops perceptions and preferences 
regarding the available channels. In the multichannel shopping context, a specific channel may be used in combination with others for the completion of a single purchase task, as is the case with web-rooming and show-rooming behavior (Beck and Rygl, 2015; Verhoef et al., 2015), and consumers' channel preferences at each stage will also be influenced by their perceptions and preferences with respect to other options. It is also well documented in the literature that these tasks imply different degrees of cognitive burden and that the more complex the tasks are, the longer they take to complete (Wang et al., 2014).

Therefore, our first proposition is:

Proposition 1. Website task completion time varies with task complexity, being longer for website exploration or the evaluation of purchase options than it is for the actual purchase once the evaluation and search stages are complete.

Regarding the AOIs, Van Duyne et al. (2003) define four key features of web design patterns: navigation area, brand content area, product content area and related links. The first three are the most important features of an e-commerce site. The layout and appearance of these areas are included in the design features, while the number of menu levels, the depth of description, and others, are content features (Huizingh, 2000; Katz and Byrne, 2003); both types are key influencers of website quality perception (Al-Qeisi et al., 2014). According to Huizingh (2000), “... content refers to the information, features, or services that are offered in the Web site; design, to the way the content is made available for Web visitors". These content features are among the website-quality assessment tools identified and developed by IT and marketing researchers (Chiou et al., 2010). However, as noted by Dedeke (2016), website quality measurements usually integrate evaluations of website content features with others, such as 
speed and ease of use, or security, thus complicating the task of analyzing their individual impact on consumer perceptions through the different stages of the path to purchase.

We can distinguish three main AOIs in an e-commerce website. The first is the header, which serves to define intention and content (Holzschlag, 1998) and usually includes at least the name of the firm and, often, contact details. The header presents the company identity and brand logo. Huizingh (2000) refers to this and the product area as "marketing information areas". The usefulness of the information will depend on the goal of the user, since the company's identity may be irrelevant when navigating for purposes other than brand assessment. Thus, our second proposition states that:

Proposition 2. The header draws more attention and has a greater attention retention capacity and appeal when the user's goal is website evaluation.

Next is the key feature of a web page, the content, which, in B2C e-commerce sites, is located in the product area (Van Duyne et al., 2003). Information presentation in this area is critical for success (Flavián et al., 2010). According to Badre (2002), consumers expect products to be presented in much the same manner as in a store; therefore, the function and layout of the content area are similar to those of a shop window. However, as in the case of the header, attention levels in this area depend on the stage the consumer has attained in the purchase process, since product information is more necessary when evaluating and selecting options and for the purchase task. Therefore, our third proposition is stated as follows:

Proposition 3. The product area draws more attention and has greater attention retention capacity and appeal when the user's goal is to evaluate the options and make a purchase. 
The last key content feature is the navigation menu linking the user to the various internal pages of the website (Yu and Roh, 2002). This menu often has links to transactional information (Huizingh, 2000), enabling access to the details of payment, shipping, return and other company policies. This sort of information may be more relevant at certain points in the transaction process and during overall evaluation of a specific site and less relevant for tasks relating to the evaluation of options. Thus, our fourth and last proposition states that:

Proposition 4. The service navigation menu commands more attention and has greater attention-grabbing and retention capacity during general exploration tasks and postpurchase tasks.

To conclude, it is worth noting those subject-dependent top-down factors influencing the attentional process such as the product involvement and online consumer experience. Product involvement is dependent on the consumers' inherent needs, values and interests (Zaichkowsky, 1985) and leads to an attentive state of mind that makes consumers more capable of processing information (Belanche et al., 2017; Yoo et al., 2004). Conversely, the online experience can create automaticity, allowing habitual behaviors to be performed easily and quickly (Wood et al., 2002). These variables are considered additional subject characteristics affecting the attentional process.

\section{Research design}

We test the above propositions by means of an experimental design. 


\subsection{Subjects and design}

The research team recruited a random selection of 58 students from the fourth year of a degree course in Business Administration and Management from a university in Spain; they were then invited to a quiet laboratory without distractions and with controlled lighting conditions where the data were to be collected. The choice of students may have an impact on the representativeness of our sample. However, there were several reasons suggesting that restricting the survey population to university students may be a minor problem. The 25- to 34-year-olds comprised the second largest segment (20.6\%) of online purchasers in Spain in 2017, while the higher education population represents $34.3 \%$ (ONTSI, 2018). The product categories selected for the experimental tasks (sport shoes, mobile phone, ball-point pens, and hard disks) are popular as online purchases among university students. A further circumstance is that the previous studies that have used the eye-tracking method to collect attention and fixation data during website tasks also used students as their subjects (Djamasbi et al., 2010; Leuthold et al., 2011; Reutskaja et al., 2011; Shi et al., 2013; Velásquez, 2013). However, this usage is not the case in ad attention studies, where randomly selected consumer samples are used (Pieters and Wedel, 2004; Wedel and Pieters, 2000).

This study uses an intrasubject design including four tasks (exploration, search, purchase, and after sale) $\mathrm{x}$ four websites (sport shoes, mobile phone, ball-point pens, and hard disks). This design has the advantage of controlling both for individual effects and for potential bias from the learning effect, which appears as the subjects progress through the required tasks (Gentile et al., 1972). Thus, all subjects are required to perform all four tasks and to visit all four stores 
(categories); however, the task-store pairs are random combinations, such that no subject repeats the same task in the store to avoid interference from the learning effect.

\subsection{Materials}

\section{Materials: websites and AOIs}

The experimental design was implemented by creating four simulated web stores, one for each of the four different product categories. Such simulation is not new to this type of research (Leuthold et al., 2011; Wang et al., 2014) and, although it reduces the degree of realism, it enables stricter control of other effects that might bias the results. This simulation uses a naturallooking e-commerce website layout enabling unambiguous location of the three AOIs as found in most countries worldwide (Bernard and Sheshadri, 2004). Thus, the first AOI, the header showing the company identity, appears at the top and centered and has a menu with contact details, the "Home" button on the left and the shopping cart on the right. The second AOI, the product offer, occupies the center-screen below the header. This AOI has the appearance of a shop-window displaying product names, images of the goods and prices and add-to-cart buttons below. The third AOI, services, appears on the left below the header. We use the AOI classification that is shown in Figure 2.

The product category can affect both the time spent completing the task and how much attention is focused on the web page. This effect is mitigated by including these four different product categories with different degrees of risk and including both search and experience products (Mitra et al., 1999). The four categories are sports shoes, mobile phones, ball-point pens and hard disks. The same layout is used for all four stores, with variation in the colors but in no 
other features to avoid other potential biases. Images of all four web stores are provided in Annex 1.

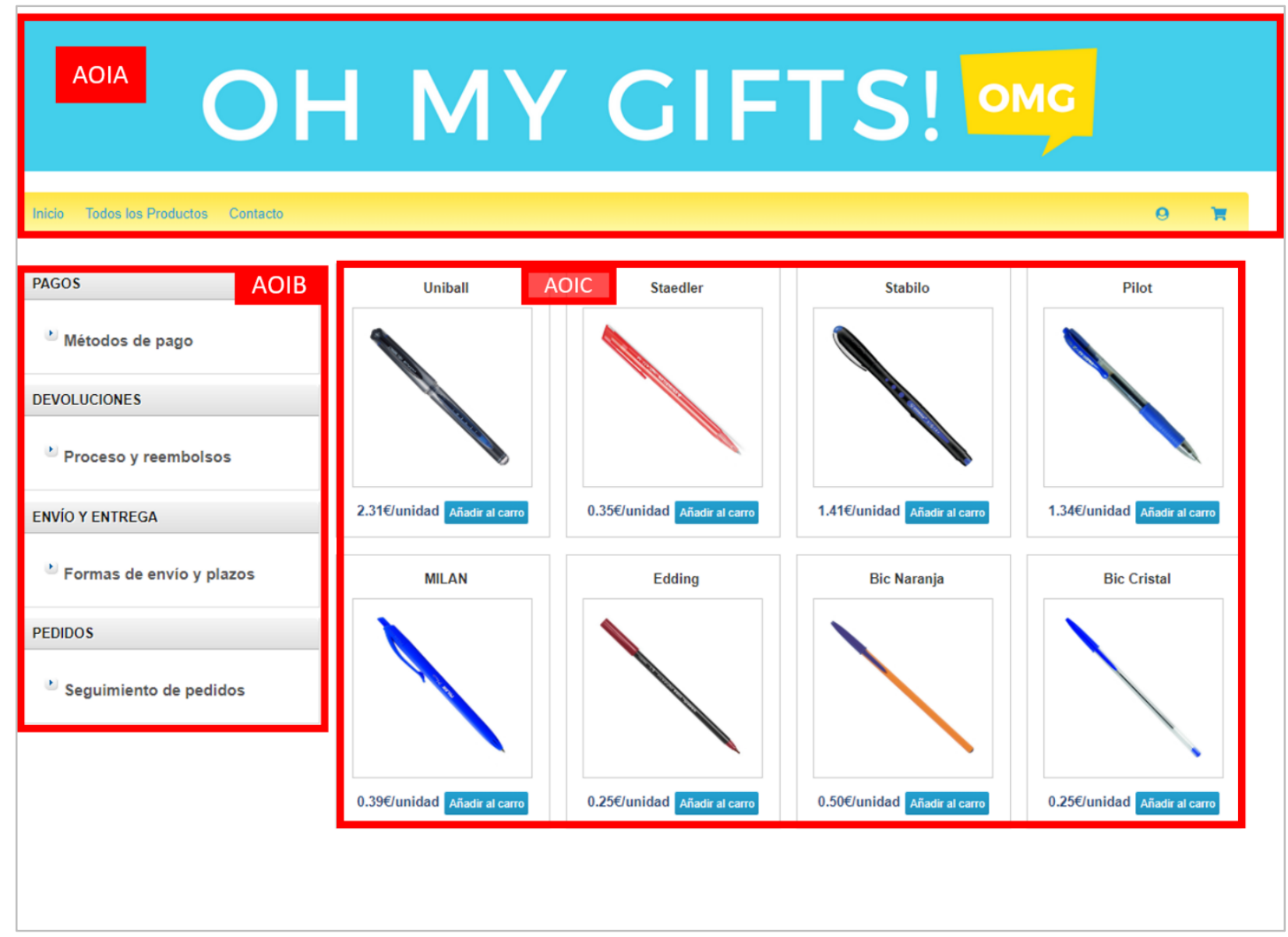

Figure 2. Definition of AOIs.

\section{Materials: task definitions}

Before task definition, qualitative interviews were conducted following a pretest. The tasks are analogous to those used for each stage in previous studies (Leuthold et al., 2011; Reutskaja et al., 2011; Shi et al., 2013; Wang et al., 2014). One task per stage is set in addition to one more for control purposes. The individuals encounter four tasks:

- Task 1 Exploration Task (control): "rate the website for overall appeal" 
- Task 2 Search Task: "visit the website and select from those offered the product that most appeals to you based on the information provided"

- Task 3 Purchase Task: "add option X to the shopping cart"

- Task 4 Postpurchase: "find how to track your order"

\subsection{Procedure}

The study occurred in April 2018. A random sample of 58 students was recruited by the research team. Eligible recruits were shown into the laboratory and seated at individual computer terminals where they were to perform the 4 tasks and complete a questionnaire. After calibration, the questionnaire became accessible, and the tasks could begin. As an incentive, participants received numbers in a draw for a $20 €$ Amazon shopping voucher. Given the profile, the sample was highly homogeneous with regard to age (mean age 24.8 , with a standard deviation of 4.7 ) and occupation (94\% were full-time students). More than half (60\%) were women.

The procedure is shown in Figure 3. Each subject was randomly assigned to randomly formed task/category pairs, such that each subject completed all four tasks and visited the four stores; however, the category in which each subject completed each task and the order in which the tasks were completed were different for each subject. Store-task pair assignment and questionnaire implementation required another platform, in this case, the Qualtrics online platform. The questionnaire was linked to the four web stores such that, when the task for a certain category appeared on screen and the subject pressed the store access button, the time spent in the store until the first click was registered and the subject returned to the questionnaire. 


\section{EXAMPLE: Task flow}

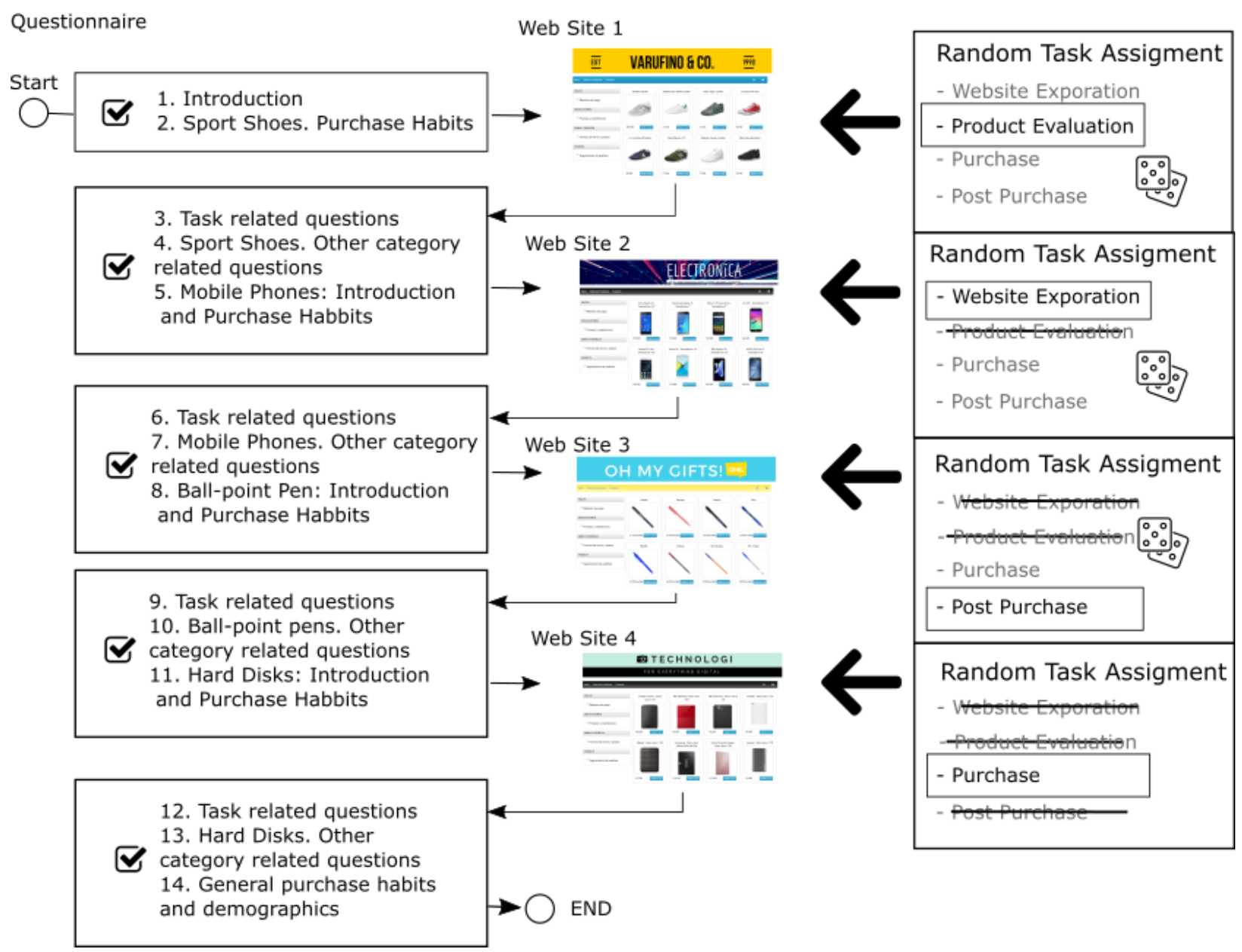

Figure 3. Example Sequence of Tasks and Stores for one subject

We did not explicitly measure the success or failure of each task, as the subjects returned to the questionnaire when they clicked anywhere on the screen. However, we measured this dimension implicitly for the four tasks as we asked the participants to rate the attractiveness of the webpage in the first task, to select the chosen product in the second task and to rate how difficult the task has been for them in the case of tasks 3 and 4 .

Data collection, including eye tracker instrument calibration, questionnaire completion and associated tasks, took an approximate total of 15 minutes per person. Subjects were accompanied by a researcher throughout this process. 


\subsection{Method}

This experiment enabled us to obtain observational (eye-tracking) data and declarative feedback (questionnaire responses) from each subject. The subjects' level of attention across task types was measured by means of purpose-designed eye-tracking hardware comprising cameras and infrared light. The specific choice of hardware for this study was The Eye Tribe Tracker. According to its manufacturers, The Eye Tribe Tracker has an average accuracy of $0.5^{\circ}$, a spatial resolution of $0.1^{\circ}(\mathrm{rms})$ and an average frame rate of $30 \mathrm{~Hz}$. The system monitors the subject's gaze throughout the trial and registers eye fixations according to a specified spatial dispersion criterion.

A fixation is defined as a quasi-stable position of the eye for a minimum of 200 milliseconds. The requirement for a quasi-stable position requires that the angular dispersion of the eye is below $1^{\circ}$. The fixation check procedure filters out noise in the gaze data. The procedure only records fixations within the selected AOIs; thus, outliers in the gaze patterns are filtered out. Once the trial is complete, the gaze position coordinates and time patterns across the four tasks are taken and the subject's fixation times are recorded and classified by AOI and type of task. We computed attention indicators such as the number of gaze fixations on each area of interest (to show the relative importance of each area) and the transfers between AOIs (exploration pattern). The data on transitions between areas for each task were used to create individual AOI transfer matrices.

This information was completed with declarative feedback from the questionnaire to control for potentially unobserved subject characteristics that might affect attention and time spent on task. The questionnaire included information regarding purchase habits, category involvement 
and sensitivity to brands, prices and services. Finally, subject characteristics, such as online shopping experience, and demographics were included for control purposes (see full questionnaire in Annex 2). The individual attention patterns obtained by eye-tracking were linked to the declarative data from the questionnaire by a unique code generated by Qualtrics for each questionnaire. The metrics employed in this study are as follows:

- Task completion time: task completion time in seconds.

- Total fixations by AOI: subject total fixations weighted by the relative surface area of the AOI and by the subject's total number of fixations on the task.

- Proportions of transfers between AOIs: we calculate the proportion of transfers from one area to another within each purchase task.

- Involvement with the category: This measure was obtained by means of a questionnaire. Respondents were requested to indicate on a scale of 1-7 their level of agreement (1disagree strongly, 7-agree strongly) with three statements: "My Knowledge of X (name of product category) is very good", "It is important for me to make the right choice when shopping for X (name of product category)", and "I find shopping for X (name of product category) interesting". The involvement construct was based on the factor analysis of these three questionnaire items (Annex 2, Q6.1, Q6.2 and Q6.3) for each of the four categories. The Cronbach's Alpha scale reliability coefficient was 0.69 for the sports shoes category, 0.81 for the mobile phones, 0.77 for the ball-point pens, and 0.73 for the hard disks (Cronbach, 1951). 
- Ease with online information seeking: This measure was obtained by means of a questionnaire. Respondents were requested to rate their degree of ease in finding information through the Internet (0-extremely low; 10-extremely high).

- Online shopping experience: This measure was obtained by means of a questionnaire. Respondents were requested to rate their degree of ease in shopping through the Internet ( 0 extremely low; 10-extremely high).

\section{Results and discussion}

\subsection{Descriptive results}

Figure 4 shows the box plots for time spent per task. It can be observed that the task requiring the longest average time is the choice of product option (Task 2) (20 seconds on average), followed by the website exploration task (Task 1). On average, the purchase task (Task 3) and the order tracking task (Task 4) take less time.

Figure 5 shows the so-called "heat map" for each task in the case of the first store, the sport shoes store, which provides a visual representation of the attention scores per area. The maps show how the total number of fixations is distributed across the screen, with the deeper red areas indicating which parts of the screen attracted the highest numbers of fixations and the green areas indicating those that drew the least attention. It can be observed at a glance that attention is more dispersed during the website exploration task (Task 1), more concentrated on the product area during the information seeking task (Task 2), closer to the specific option that must be located to add it to the cart during the purchase task (Task 3), and more on the side menu during 
the postpurchase or order-tracking task (Task 4). We also include heatmaps for the three other stores in Annex 3. It can be observed that inspecting the four stores leads to similar conclusions.

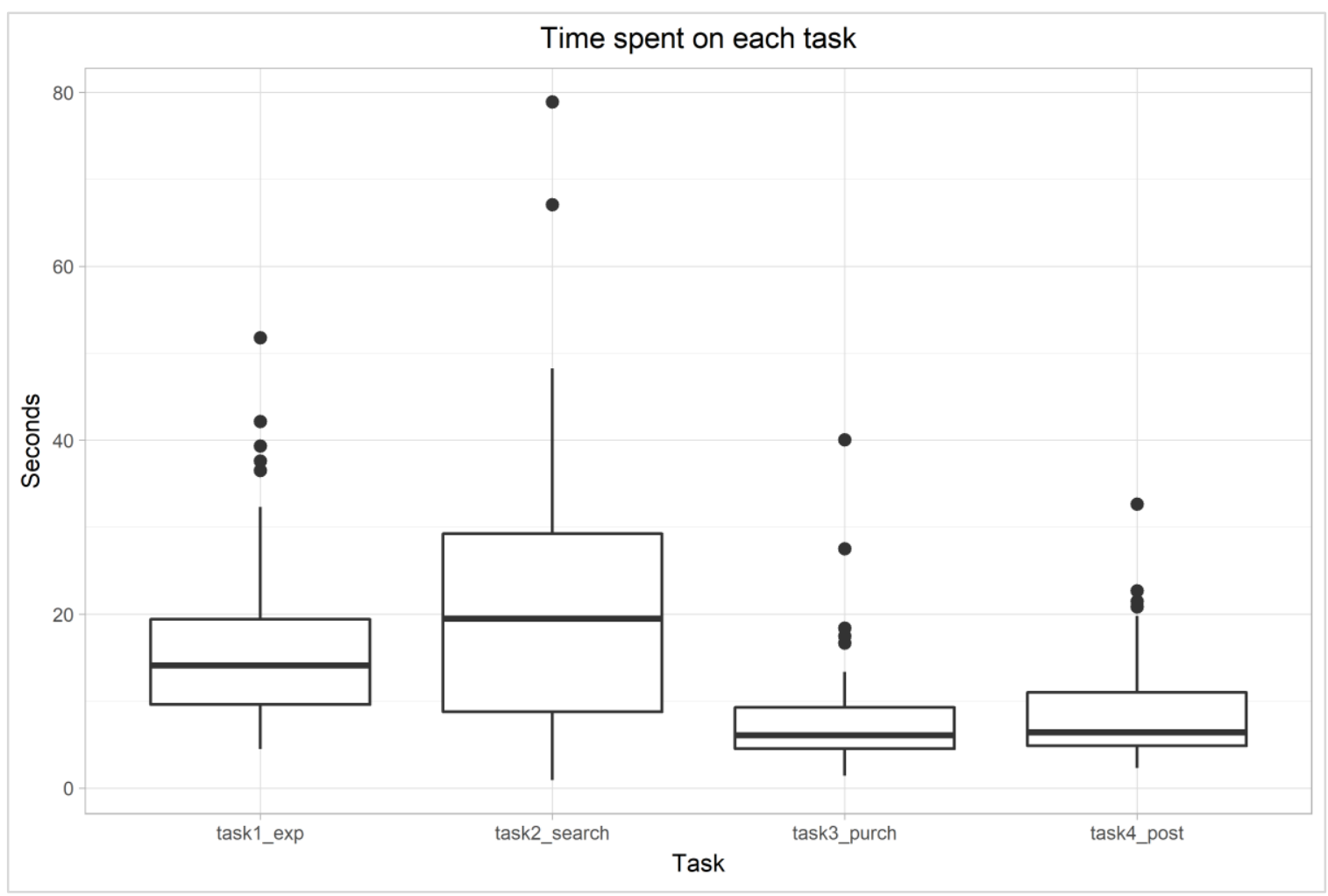

Figure 4. Box Plots for time spent on tasks (seconds) 


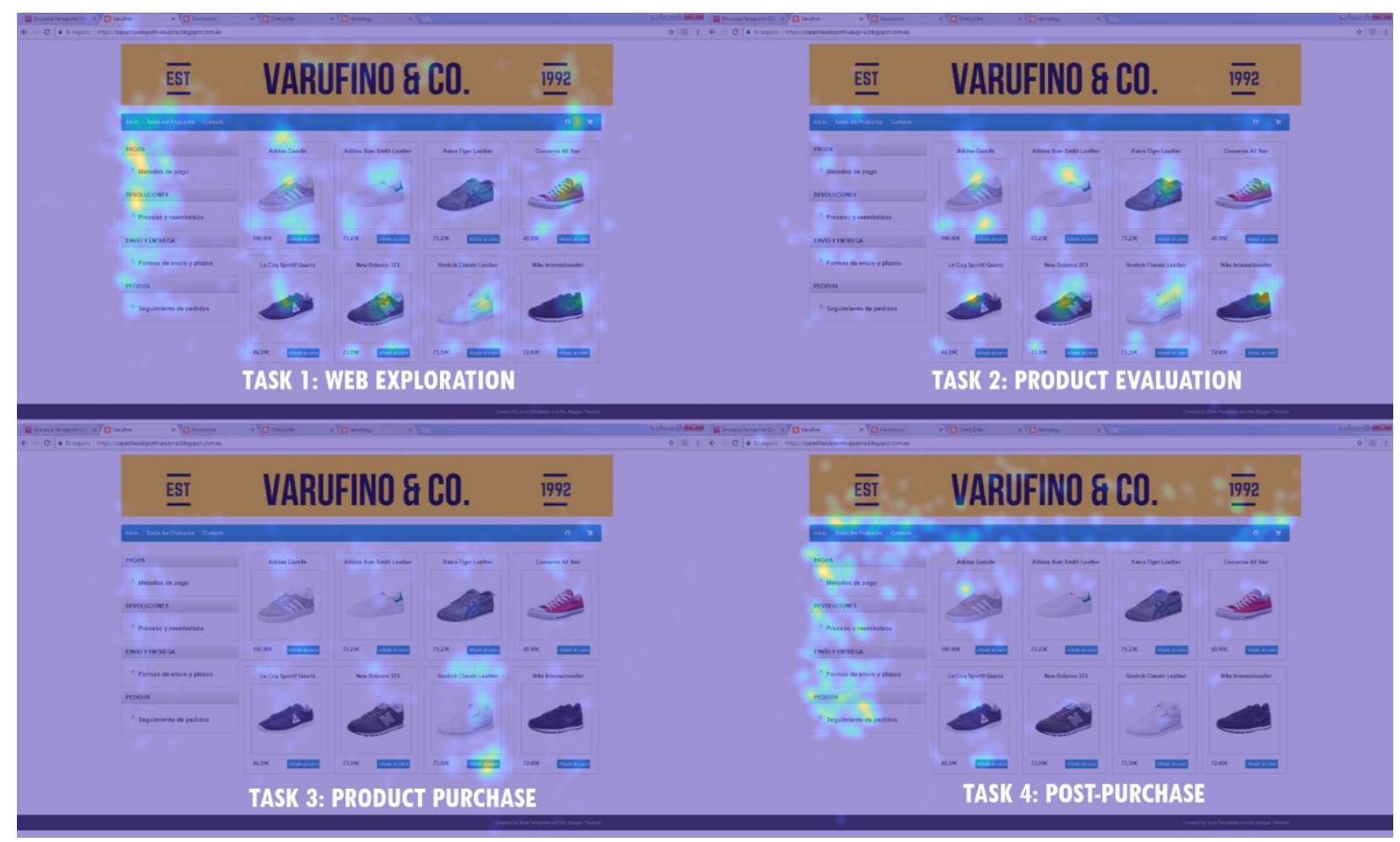

Figure 5. Heat Maps. Aggregated Fixations by task. Sport Shoes Store. 
Figure 6. Boxplots. Fixations by Zone and Task
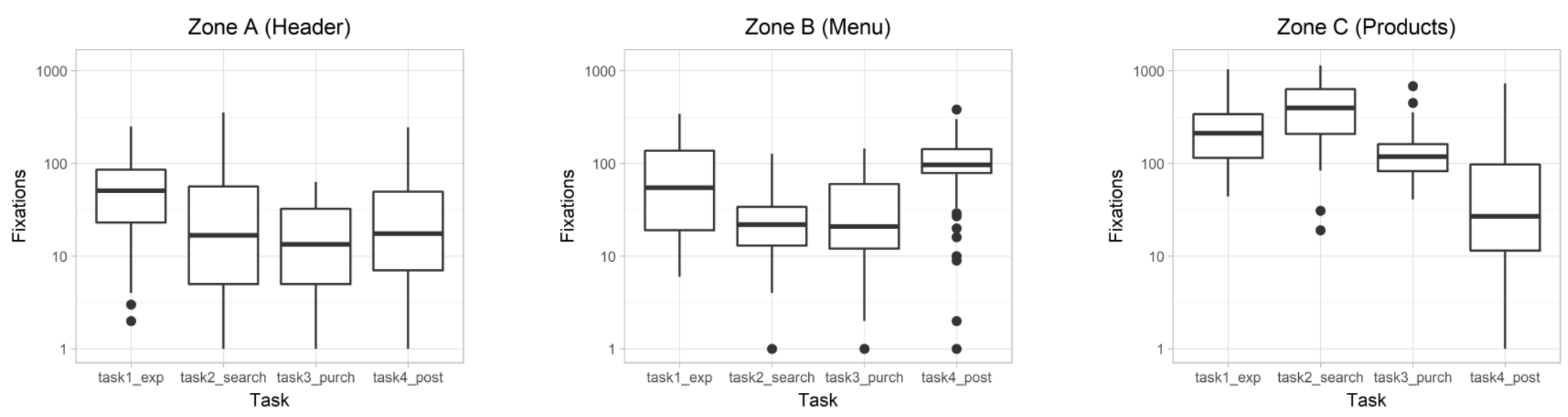
Figure 6 shows the numerical distribution of the fixations per area, per task. Figure 6 shows that AOI A, which relates to brand identity (header), presents fewer fixations than the other two areas and only garners higher attention during the exploration task (Task 1). The service menu area (area B) has more fixations during the postpurchase task (Task 4), while the product area (area C) draws more attention during the options evaluation (Task 2) and purchase tasks (Task 3).

As supplementary material, we provide slow-motion video images of subjects' fixation patterns during the various tasks.

Insert here link to videos $1,2,3$ and 4

The exploration video (Task 1) shows how subjects transfer their attention between the three AOIs, beginning in the product area, before moving to the header and finally to the services menu. However, in the purchase task (Task 3), (the required product is third in the bottom row) after a brief exploration of the header and side menu, the subject's attention fixates on the product area until the required product is located (purchase task video). See also the two example videos for the information-seeking (Task 2) and postpurchase tasks (Task 4).

With respect to feedback from the questionnaire, Table 1 provides a summary of the descriptive data for category involvement indicators and familiarity with online search of information and purchase.

Sports shoes and mobile phones are both high-interest products. The hard disk, despite being the least known, is a high-importance and high-interest product due to its price. The opposite is true of ball-point pens, which are low-importance and low-interest products. The mobile phone is 
the category that generates the most interest. The values for "ease with online information seeking and purchase processes" are high with very low standard deviation.

Table 1. Descriptive statistics

\begin{tabular}{lcccc}
\hline Variable & Mean & SD & Min. & Max \\
\hline Knowledge & & & & \\
Knowledge_Sport shoes & 4.483 & 1.417 & 1 & 7 \\
Knowledge_Mobile phones & 4.190 & 1.456 & 1 & 7 \\
Knowledge_Ball-point pens & 3.362 & 1.347 & 1 & 6 \\
Knowledge_Hard disks & 2.724 & 1.684 & 1 & 7 \\
Importance & & & & \\
Importance_Sport shoes & 5.534 & 1.127 & 2 & 7 \\
Importance_Mobile phones & 6.138 & 1.317 & 2 & 7 \\
Importance_Ball-point pens & 2.983 & 1.516 & 1 & 7 \\
Importance_Hard disks & 4.931 & 1.520 & 1 & 7 \\
Interest & & & & \\
Interest_Sport Shoes & 5.224 & 0.992 & 3 & 7 \\
Interest_Mobile phones & 4.966 & 1.737 & 1 & 7 \\
Interest_Ball-point pens & 2.707 & 1.451 & 1 & 7 \\
Interest_Hard disks & 3.897 & 1.754 & 1 & 7 \\
Ease with online information seeking & 8.103 & 1.435 & 4 & 10 \\
Ease with online shopping & 7.293 & 1.727 & 2 & 10 \\
\hline
\end{tabular}

\subsection{Modeling process (I)}

Although in the descriptive analysis, we observe differences in the attention to the AOIs according to the task, to dig deeper into these relationships, we construct more general models that jointly consider the effect not only of the task but also of the product category and personal characteristics included in the questionnaire.

We construct three different models with three dependent variables: the time spent by each subject on the task, the number of fixations made by each subject while engaged in each task and the probability of transfer between AOIs in each individual transfer matrix. The number of 
observations is the same for all models, that is, a panel with 232 observations (number of subjects: 58 x number of tasks: 4).

As in all of these models, the same individual provides four observations; fixed effects models are used in all cases to explain this intrasubject correlation (Carey and Wang, 2001), as we allow the constant term for each model to be different by subject and correlated with the regressor matrix. The models for time and total fixations are fixed effects regression models, as the dependent variables are continuous, while the models for transitions probabilities are fixed effects logistic regressions, as the dependent variable varies between 0 and 1 (Agresti, 2003).

The independent variables are the same ones previously noted in section 3.4 for all models: task, product category, involvement with each category, ease with online information seeking and Internet shopping experience.

\section{Modelization 1: Time spent on task}

The model to be estimated for task completion time takes the following form:

\section{Model 1: Task completion time}

$$
\begin{gathered}
y_{i j}=\alpha_{i}+\sum_{j=1}^{4} \beta_{j} \operatorname{Task}_{i j}+\sum_{z=1}^{4} \gamma_{z} \text { Cat }_{z}+\rho_{1} \operatorname{Inv}_{i}+\rho_{2} \text { Search }_{i}+\rho_{3} \text { Purchase }_{i}+e_{i j} \\
\alpha_{i}=\alpha+u_{i}
\end{gathered}
$$

where:

$y$ is the task completion time in seconds, as per readings obtained from the eye-tracking experiment and the store link script 
$i$ is the subject, with $i=1 \ldots . .58$

$j$ is the task subindex, and the dummies are 1: exploration (Task $\left.k_{1}\right), 2$ : information seeking $\left(\operatorname{Tas}_{2}\right), 3:$ purchase $\left(\operatorname{Tas}_{3}\right)$, and y 4: post purchase $\left(\operatorname{Tas}_{4}\right)$

$\alpha_{i}$ is the constant term for the model, which varies with the subject

$\beta_{j}$ are the parameters for the effect of the task relative to the control 0 (website exploration)

$\gamma_{z}$ : parameters for the category effect, where the dummies are $\operatorname{Cat}_{1}$ : sports shoes, $\mathrm{Cat}_{2}$ : mobile phones, $\mathrm{Cat}_{3}$ : ball-point pens, and $\mathrm{Cat}_{4}$ : hard disks

$I n v_{i}$ : subject $i$ 's involvement with the category in which the task is performed, based on questionnaire feedback

$\operatorname{Search}_{i}$ : subject $i$ 's ease with online information seeking, based on questionnaire feedback

Purchase $e_{i}$ : subject $i$ 's ease with online shopping, based on questionnaire feedback

$\rho_{1}$ parameter for the subject's level of involvement with the category based on the factor analysis of three questionnaire items

$\rho_{2}$ parameter for the subject's level of ease with online information seeking

$\rho_{3}$ parameter for ease with online shopping

$e_{i j}$ and $u_{j}$ are the estimation error terms

We apply a linear mixed-effects estimation in R (v6.0.0) (Bates et al., 2014).

Table 2 shows the results of this estimation. The results suggest that the task completion time varies considerably, according to the desired goal, around a global mean of 20'. Thus, 
information-seeking takes significantly longer than exploration (parameter 4.299), while the two simpler tasks, purchase and after sales, take significantly less time than either of the aforementioned (parameters -8.762 and -8.620). These findings are consistent with the first proposition that the website task completion time is longer for the exploration or evaluation of purchase options than it is for the actual purchase.

Table 2. Model 1. Seconds per task

\begin{tabular}{|c|c|c|c|}
\hline & Estimate & Std. Error & p value \\
\hline Intercept & 19.762 & 5.384 & 0.000 \\
\hline \multicolumn{4}{|c|}{ Task (base exploration) } \\
\hline Search & 4.299 & 1.707 & 0.012 \\
\hline Purchase & -8.762 & 1.666 & 0.000 \\
\hline After Sale & -8.620 & 1.699 & 0.000 \\
\hline \multicolumn{4}{|c|}{ Category (base sport shoes) } \\
\hline Mobile phones & 4.123 & 1.806 & 0.022 \\
\hline Ball-point pens & -2.062 & 1.850 & 0.265 \\
\hline Hard disks & 1.834 & 1.708 & 0.283 \\
\hline Involvement & -0.346 & 0.262 & 0.186 \\
\hline Search Online & -0.080 & 0.896 & 0.929 \\
\hline Purchase Online & 0.015 & 0.747 & 0.984 \\
\hline
\end{tabular}

\begin{tabular}{lrr}
\hline Random part & & \\
\hline & Variance & Std.Dev. \\
\hline Subject & 22.680 & 80.239 \\
\hline Residual & 4.762 & 8.958 \\
\hline Fit & & \\
\hline AIC & 1.743 .581 & \\
\hline BIC & 1.784 .942 & \\
\hline Residual DF & 220.000 & \\
Subjects & 58.000 & \\
\hline
\end{tabular}

Note: Linear mixed model fit by maximum likelihood 
With respect to the category effect, it should first be noted that, after controlling for the task effect, the time spent on the task is no shorter in the categories presented last (ball-point pens and hard disks) than in those presented first (sports shoes), which suggests that there are no serious problems deriving from the learning effect in this design. The only significant effect, which is found in the mobile phone category, can be interpreted as the result of its being the highestinterest category in average terms. Finally, the observed effect for ease with online information seeking and online shopping is close to zero, possibly due to the high homogeneity of the subject sample in this respect.

\section{Modelization 2: Gaze patterns across AOIs}

Next, differences in the levels of attention across the various AOIs are analyzed by aggregating all of each subject's fixations on the first AOI, labeled A (header and upper menu), on AOI B (service menus) and on AOI C (products). Given the size differences between AOIs, total fixations are weighted by the relative surface area of the AOI and by the subject's total number of fixations on the task. Three equations are estimated, one per AOI, for $k=1,2,3$ to measure the level of attention to the three areas of interest while controlling for product category and individual characteristics:

\section{Model 2: Attention by AOIs: Total fixations by AOI}

$$
\begin{aligned}
& \quad y_{i j k}=\alpha_{i k}+\sum_{j=1}^{4} \beta_{j k} \text { Task }_{j k}+\sum_{z=1}^{4} \gamma_{z k} \operatorname{Cat}_{z}+\rho_{1 k} \operatorname{Inv}_{i}+\rho_{2 k} \operatorname{Search}_{i}+\rho_{3 k} \text { Purchas }_{i}+ \\
& e_{i j k} \\
& \quad \alpha_{i k}=\alpha+u_{i} \text { for } k=1,2,3
\end{aligned}
$$

where: 
$y$ is the total number of fixations made by subject $i$ while engaged in task $j$ on AOI $k$

$i$ is the subject where $i=1 \ldots .58$

$j$ is the task subindex where the dummies are 1: exploration $\left(\operatorname{Tas}_{1}\right), 2$ : information seeking $\left(\operatorname{Task}_{2}\right)$, 3: purchase (Task $\left.{ }_{3}\right)$ and 4: after sales $\left(\operatorname{Tas}_{4}\right)$

$k$ is the area of interest, where 1 is the header, 2 is the side menu, and 3 is the content area $\alpha_{k}$ is the constant term for the exploration area, which varies with the subject and the AOI $\beta_{j k}$ are the parameters for the task effect in AOI $k$

$\gamma_{z k}$ : parameters for the category and AOI effects, where the dummies are $\mathrm{Cat}_{1}$ : sports shoes, $\mathrm{Cat}_{2}$ : mobile phones, $\mathrm{Cat}_{3}$ : ball-point pens, and $\mathrm{Cat}_{4}$ : hard disks

$\operatorname{In} v_{i}$ : subject $i$ 's involvement with the category in which the task is performed

Search ${ }_{i}$ : subject $i$ 's ease with online information seeking

Purch $i$ : subject $i$ 's ease with online shopping

$\rho_{1 k}$ parameter for the subject's category involvement in AOI k, based on factor analysis of three questionnaire items

$\rho_{2 k}$ parameter for ease with online information seeking

$\rho_{3 k}$ parameter for ease with online shopping

$e_{i j k}$ and $u_{j}$ are the error terms 
Table 3. Model 2. Fixations by Area

Area A (Header)

Area B (Menu)

Area C (Products)

\begin{tabular}{|c|c|c|c|c|c|c|c|c|c|}
\hline & Estimate & Std. Error & p value & Estimate & Std. Error & $p$ value & Estimate & Std. Error & p value \\
\hline Intercept & 0.013 & 0.014 & 0.349 & 0.028 & 0.014 & 0.036 & 0.329 & 0.050 & 0.000 \\
\hline \multicolumn{10}{|c|}{ Task (base exploration) } \\
\hline Search & -0.035 & 0.005 & 0.000 & -0.020 & 0.006 & 0.000 & 0.116 & 0.018 & 0.000 \\
\hline Purchase & -0.033 & 0.005 & 0.000 & -0.014 & 0.005 & 0.012 & 0.066 & 0.017 & 0.000 \\
\hline After Sale & -0.015 & 0.005 & 0.006 & 0.061 & 0.006 & 0.000 & -0.164 & 0.018 & 0.000 \\
\hline \multicolumn{10}{|c|}{ Category (base sport shoes) } \\
\hline $\begin{array}{l}\text { Mobile } \\
\text { phones }\end{array}$ & 0.002 & 0.006 & 0.722 & -0.008 & 0.006 & 0.196 & 0.003 & 0.019 & 0.869 \\
\hline $\begin{array}{l}\text { Ball-point } \\
\text { pens }\end{array}$ & -0.008 & 0.006 & 0.170 & -0.013 & 0.006 & 0.025 & 0.055 & 0.019 & 0.004 \\
\hline Hard disks & -0.005 & 0.005 & 0.339 & -0.009 & 0.006 & 0.126 & 0.021 & 0.018 & 0.239 \\
\hline Involvement & -0.001 & 0.001 & 0.520 & -0.001 & 0.001 & 0.470 & 0.003 & 0.003 & 0.326 \\
\hline Search Online & 0.005 & 0.002 & 0.048 & -0.003 & 0.002 & 0.236 & -0.006 & 0.008 & 0.480 \\
\hline $\begin{array}{l}\text { Purchase } \\
\text { Online }\end{array}$ & 0.000 & 0.002 & 0.877 & 0.004 & 0.002 & 0.024 & -0.006 & 0.007 & 0.378 \\
\hline \multicolumn{10}{|l|}{ Random part } \\
\hline & Variance & Std.Dev. & & Variance & Std.Dev. & & Variance & Std.Dev. & \\
\hline Subject & 0.000 & 0.001 & & 0.000 & 0.001 & & 0.001 & 0.009 & \\
\hline Residual & 0.009 & 0.028 & & 0.006 & 0.029 & & 0.039 & 0.092 & \\
\hline \multicolumn{10}{|l|}{ Fit } \\
\hline AIC & -952.923 & & & -948.070 & & & -392.129 & & \\
\hline $\mathrm{BIC}$ & -911.562 & & & -906.709 & & & -350.768 & & \\
\hline Residual DF & 220.000 & & & 220.000 & & & 220.000 & & \\
\hline Subjects & 58.000 & & & 58.000 & & & 58.000 & & \\
\hline
\end{tabular}


The three equations, one for each AOI, are estimated as linear mixed-effects models $\mathrm{R}$ (v6.0.0) (Bates et al., 2014). The first three columns in Table 3 after the row names show the parameters for the fixations on AOI A, which, based on the negative statistical significance of the parameters of the AOI dummies, is more important in the website exploration tasks (baseline task, Task 1) than in the purchase-related tasks, particularly the actual purchase (Task 3). Columns 5, 6 and 7 provide the estimates for attention to AOI B, (the menu), which is much more important in postpurchase tasks (Task 4), although it also draws a greater number of fixations during exploration tasks (Task 1) than during options evaluation (Task 2) and purchase (Task 3). From the last three columns, it can be observed that AOI C is, as expected, the focus of attention when evaluating options and making the purchase. These findings are consistent with the second, third and fourth propositions.

Regarding the effects of the control variables, although the attention patterns for AOI A show no significant differences across categories, the level of attention to the services menu (third, fourth and fifth columns) is significantly higher in the sports shoes category (presented in the first place) than in the ball-point pen category (presented in second to last place), which might suggest a learning effect in this AOI. In this case, the origin of the differences cannot be identified. In the product AOI (last three columns), the only significant effect is a higher level of attention in the ball-point pen category. There are no observable effects from category involvement or ease with the online environment, except on the attention levels to the header, where the effect of ease with online search is significant at the 5\% level, and the menu area, where the effect of ease with online shopping is significant at the $5 \%$ level. 


\section{Modelization 3: Exploration patterns}

Finally, the dependent variable in the exploration pattern models is the probability of transfer between AOIs in the individual transfer matrix, where the minimum and maximum probabilities are 0 and 1 , respectively, which means that a linear model is inadequate; therefore, mixed effects logistic regression is used instead (Agresti, 2003).

The models in this case use the same independent variables as in the previous cases; however, each probability of transfer between AOIs is expressed as:

Model 3: Exploration patterns. Transitions between AOIs

$\operatorname{Prob}\left(y_{i j}=1 \mid X_{i j}\right)=\frac{\exp \left(b_{0}+b_{1 j} X_{1 i j}+\ldots+b_{z j} X_{i j z}\right)}{1+\exp \left(b_{0}+b_{1 j} X_{1 i j}+\ldots+b_{z j} X_{i j z}\right)}$

where:

$\left.\operatorname{Prob}\left(y_{i j}=1 \mid X_{i j}\right)\right)$ is the probability of subject $i$ 's attention relocating from one AOI to another in task $j$, subject to all the variables.

Exploration levels and patterns are analyzed by calculating the between-AOI transfer probability matrices (Gehrer et al., 2018) shown in Figure 7, where the diagonal indicates the probability of fixation remaining in a given AOI, while the cells above and below the diagonal indicate the probability of between-AOI transfers during each task.

Overall, it can be observed that the probability of transfer is highest during exploration (Task 1), lowest in the postpurchase stage (Task 4), and not very high during the search (Task 2) and purchase stages (Task 3), except in the content area. The diagonals in all four matrices indicate the expected effects, except in the case of the postpurchase task, where, although the service 
menus in AOI B show, as expected, the highest probability of attention retention (0.484), retention is also high $(0.370)$ in content area $\mathrm{C}$. This effect may be due to the interest generated by the content AOI, where the product information is richer and more varied and includes images, which have greater attention-grabbing capacity than text (Hausman and Siekpe, 2009; Yandandul, Chaitra and Paryani, Sachin and Le, Madison and Jain, 2018).

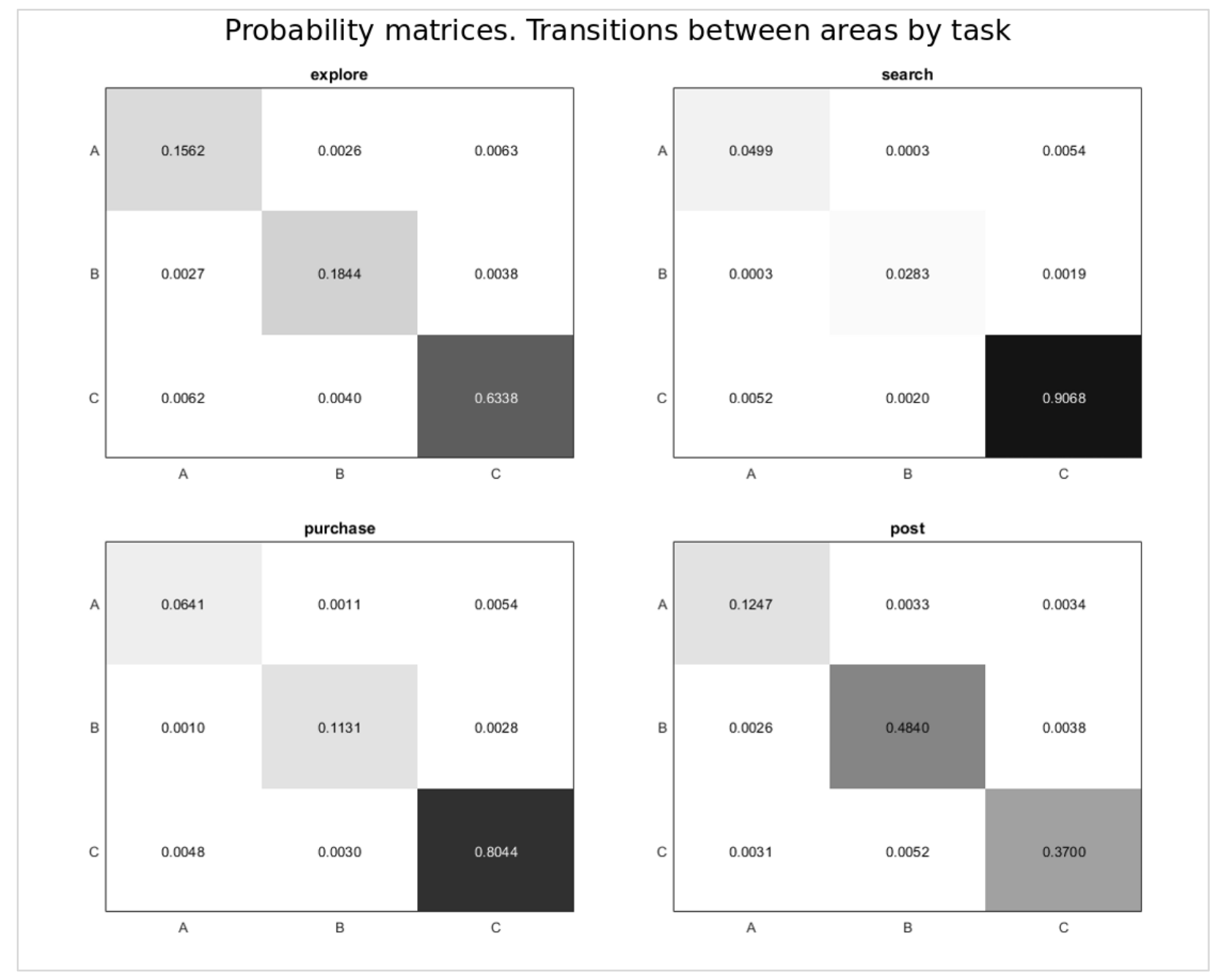

Figure 7. Transition matrices 
Table 4A. Model 3. Generalized Mixed Effects Regression. Probability Transitions to Area A (Header)

\begin{tabular}{|c|c|c|c|c|c|c|c|c|c|}
\hline & \multicolumn{3}{|c|}{ Transitions Area A (Header) -> Area A } & \multicolumn{3}{|c|}{ Transitions Area B (Menu) -> Area A } & \multicolumn{3}{|c|}{ Transitions Area C (Products) -> Area } \\
\hline & Estimate & $\begin{array}{r}\text { Std. } \\
\text { Error }\end{array}$ & $\operatorname{Pr}(>|z|)$ & Estimate & $\begin{array}{r}\text { Std. } \\
\text { Error }\end{array}$ & $\operatorname{Pr}(>|z|)$ & Estimate & $\begin{array}{r}\text { Std. } \\
\text { Error }\end{array}$ & $\operatorname{Pr}(>|z|)$ \\
\hline Intercept & -4.215 & 0.724 & 0.000 & -6.699 & 1.153 & 0.000 & -6.011 & 0.639 & 0.000 \\
\hline \multicolumn{10}{|c|}{ Task (base exploration) } \\
\hline Search & -1.725 & 0.078 & 0.000 & -2.433 & 0.867 & 0.005 & -0.431 & 0.250 & 0.084 \\
\hline Purchase & -1.411 & 0.071 & 0.000 & -1.394 & 0.529 & 0.008 & -0.488 & 0.251 & 0.052 \\
\hline After Sale & -0.452 & 0.059 & 0.000 & -0.102 & 0.367 & 0.780 & -0.885 & 0.284 & 0.002 \\
\hline \multicolumn{10}{|c|}{ Category (base sport shoes) } \\
\hline Mobile phones & 0.144 & 0.075 & 0.054 & -0.451 & 0.478 & 0.345 & 0.373 & 0.272 & 0.170 \\
\hline Ball-point pens & -0.331 & 0.079 & 0.000 & -0.548 & 0.483 & 0.256 & -0.069 & 0.293 & 0.813 \\
\hline Hard disks & -0.080 & 0.070 & 0.250 & -0.765 & 0.488 & 0.117 & -0.101 & 0.280 & 0.717 \\
\hline Involvement & 0.017 & 0.012 & 0.143 & 0.006 & 0.068 & 0.928 & -0.006 & 0.037 & 0.863 \\
\hline Search Online & 0.263 & 0.128 & 0.039 & 0.141 & 0.172 & 0.412 & 0.106 & 0.099 & 0.281 \\
\hline Purchase Online & 0.024 & 0.107 & 0.825 & 0.009 & 0.145 & 0.953 & 0.033 & 0.083 & 0.688 \\
\hline \multicolumn{10}{|l|}{ Random part } \\
\hline & Variance & Std.Dev. & & Variance & Std.Dev. & & Variance & Std.Dev. & \\
\hline Subject & 0.822 & 0.822 & & 0.000 & 0.000 & & 0.000 & 0.000 & \\
\hline Residual & 0.907 & 0.907 & & 0.000 & 0.000 & & 0.000 & 0.000 & \\
\hline \multicolumn{10}{|l|}{ Fit } \\
\hline$\overline{\mathrm{AIC}}$ & 2.088 .882 & & & 92.788 & & & 179.845 & & \\
\hline $\mathrm{BIC}$ & 2.126 .796 & & & 130.702 & & & 217.759 & & \\
\hline Residual DF & 221.000 & & & 221.000 & & & 221.000 & & \\
\hline Subjects & 58.000 & & & 58.000 & & & 58.000 & & \\
\hline
\end{tabular}

Note: Logistic link, optimizer BOBYQA 
Table 4A shows the model estimates for transfers from AOI A. The first model presented is for the probability of remaining in A, which is found to be higher during exploration than during the other tasks. Across categories, the upper menu has less attention-retaining capacity in the ball-point pen category, possibly due to this being a low-interest product. In terms of transfer probabilities, there is a greater likelihood of the shopper returning from the menu area to the header during the exploration stage than there is during either of the purchase tasks; however, there is equal probability of it occurring during the exploration and postpurchase tasks.

Although the header is not relevant during a postpurchase task, subjects unconsciously switch their attention to it as frequently as they do during the exploration task. With respect to transfers from $\mathrm{AOI} \mathrm{C}$, the chances of attention reshifting to the header are greatest during exploration, given that, once the product or menu area has been attained, the header is no longer taskrelevant.

Table 4B shows the three models for transitions to AOI B (lateral menu).

The models for AOI B in the first three columns show that the probability of prolonged fixation on this area is much higher during the postpurchase tasks (Task 4) and much lower during purchase (Task 3) and evaluation (Task 4). The high cross-category variation observed in relation to the attention given to this area might indicate a learning effect. This finding is one of the limitations of this type of experimental design, which precludes the testing of individual category effects. 
Table 4B. Model 3. Generalized Mixed Effects Regression. Probability Transitions to Area B (Menu)

\begin{tabular}{|c|c|c|c|c|c|c|c|c|c|}
\hline & \multicolumn{3}{|c|}{ Area B (Menu) -> Area B } & \multicolumn{3}{|c|}{ Transitions Area A (Header) -> Area B } & \multicolumn{3}{|c|}{$\begin{array}{c}\text { Transitions Area C (Products) -> Area } \\
\text { B }\end{array}$} \\
\hline & Estimate & $\begin{array}{r}\text { Std. } \\
\text { Error }\end{array}$ & $\operatorname{Pr}(>|\mathbf{z}|)$ & Estimate & $\begin{array}{r}\text { Std. } \\
\text { Error }\end{array}$ & $\operatorname{Pr}(>|z|)$ & Estimate & $\begin{array}{r}\text { Std. } \\
\text { Error }\end{array}$ & $\operatorname{Pr}(>|\mathbf{z}|)$ \\
\hline Intercept & -2.056 & 0.891 & 0.021 & -7.182 & 1.067 & 0.000 & -4.430 & 0.708 & 0.000 \\
\hline \multicolumn{10}{|c|}{ Task (base exploration) } \\
\hline Search & -1.965 & 0.090 & 0.000 & -2.550 & 0.875 & 0.004 & -0.545 & 0.351 & 0.121 \\
\hline Purchase & -0.951 & 0.063 & 0.000 & -1.472 & 0.554 & 0.008 & -0.468 & 0.329 & 0.155 \\
\hline After Sale & 2.218 & 0.052 & 0.000 & 0.277 & 0.333 & 0.405 & 0.452 & 0.275 & 0.101 \\
\hline Mobile phones & -0.344 & 0.071 & 0.000 & 0.009 & 0.431 & 0.983 & -0.581 & 0.326 & 0.074 \\
\hline Ball-point pens & -0.786 & 0.074 & 0.000 & -0.679 & 0.493 & 0.168 & -0.366 & 0.326 & 0.261 \\
\hline Hard disks & -0.702 & 0.064 & 0.000 & -0.225 & 0.423 & 0.596 & -0.454 & 0.306 & 0.137 \\
\hline Involvement & -0.065 & 0.012 & 0.000 & -0.026 & 0.061 & 0.673 & 0.019 & 0.045 & 0.668 \\
\hline Search Online & -0.090 & 0.159 & 0.569 & 0.253 & 0.159 & 0.112 & -0.087 & 0.112 & 0.435 \\
\hline Purchase Online & 0.256 & 0.132 & 0.053 & -0.038 & 0.131 & 0.775 & -0.034 & 0.093 & 0.715 \\
\hline \multicolumn{10}{|l|}{ Random part } \\
\hline & Variance & Std.Dev. & & Variance & Std.Dev. & & Variance & Std.Dev. & \\
\hline Subject & 1.314 & 1.314 & & 0.000 & 0.000 & & 0.000 & 0.000 & \\
\hline Residual & 1.146 & 1.146 & & 0.000 & 0.000 & & 0.000 & 0.000 & \\
\hline \multicolumn{10}{|l|}{ Fit } \\
\hline AIC & 3.106 .425 & & & 100.206 & & & 125.958 & & \\
\hline $\mathrm{BIC}$ & 3.144 .339 & & & 138.120 & & & 163.872 & & \\
\hline Residual DF & 221.000 & & & 221.000 & & & 221.000 & & \\
\hline Subjects & 58.000 & & & 58.000 & & & 58.000 & & \\
\hline
\end{tabular}

Note: Logistic link, optimizer BOBYQA 
Furthermore, category involvement negatively influences the attention-retaining capacity of AOI B; subjects with higher category involvement are more likely to switch from area B to more category-related areas. The capacity of this area to draw attention away from the header is equal across the exploration and postpurchase tasks and lower in the evaluation and purchase tasks. With regard to the last three columns, the probabilities of this area drawing attention away from the content area are very slight, with no significant cross-task variance, and the signs are as expected.

Finally, in Table 4C we can see that the attention-retaining capacity of the product area (AOI C) is higher during the options evaluation (Task 2) and purchase tasks (Task 3) and lower during the postpurchase task (Task 4); however, even in the latter, it plays an important role, as observation has shown, and fixation probability is higher during the associated tasks.

Here, also, a category effect is observed. This observation could be due not only to learning but also to other effects, since the effect attains its highest value in association with ball-point pens, which are third in the presentation sequence. Involvement also has a positive effect, as reflected by the longer fixation durations observed in this area. The capacity of area $\mathrm{C}$ to draw attention away from area $\mathrm{A}$ is higher during exploration and lower during the postpurchase stage, as might be expected, while the capacity of any other area to attract attention away from area $\mathrm{C}$ shows no cross-task variation. 
Table 4C. Model 3. Generalized Mixed Effects Regression. Probability Transitions to Area C (Products)

\begin{tabular}{|c|c|c|c|c|c|c|c|c|c|}
\hline & \multicolumn{3}{|c|}{ Area B (Menu) -> Area B } & \multicolumn{3}{|c|}{ Transitions Area A (Header) -> Area B } & \multicolumn{3}{|c|}{$\begin{array}{c}\text { Transitions Area C (Products) -> Area } \\
\text { B }\end{array}$} \\
\hline & Estimate & $\begin{array}{l}\text { Std. } \\
\text { Error }\end{array}$ & $\operatorname{Pr}(>|\mathbf{z}|)$ & Estimate & $\begin{array}{r}\text { Std. } \\
\text { Error }\end{array}$ & $\operatorname{Pr}(>|\mathbf{z}|)$ & Estimate & $\begin{array}{r}\text { Std. } \\
\text { Error }\end{array}$ & $\operatorname{Pr}(>|z|)$ \\
\hline Intercept & 1.949 & 0.725 & 0.007 & -5.995 & 0.621 & 0.000 & -4.597 & 0.746 & 0.000 \\
\hline \multicolumn{10}{|c|}{ Task (base exploration) } \\
\hline Search & 1.972 & 0.058 & 0.000 & -0.316 & 0.244 & 0.196 & -0.560 & 0.354 & 0.114 \\
\hline Purchase & 1.347 & 0.049 & 0.000 & -0.247 & 0.233 & 0.289 & -0.538 & 0.344 & 0.118 \\
\hline After Sale & -1.760 & 0.047 & 0.000 & -0.751 & 0.276 & 0.007 & 0.164 & 0.296 & 0.580 \\
\hline Mobile phones & 0.211 & 0.058 & 0.000 & 0.087 & 0.262 & 0.739 & -0.378 & 0.351 & 0.282 \\
\hline Ball-point pens & 0.735 & 0.058 & 0.000 & -0.042 & 0.269 & 0.877 & -0.337 & 0.361 & 0.351 \\
\hline Hard disks & 0.585 & 0.052 & 0.000 & -0.244 & 0.265 & 0.357 & -0.122 & 0.316 & 0.699 \\
\hline Involvement & 0.029 & 0.009 & 0.001 & 0.017 & 0.036 & 0.646 & 0.014 & 0.047 & 0.771 \\
\hline Search Online & -0.049 & 0.129 & 0.704 & 0.072 & 0.096 & 0.453 & -0.052 & 0.119 & 0.662 \\
\hline Purchase Online & -0.207 & 0.108 & 0.056 & 0.051 & 0.081 & 0.526 & -0.063 & 0.099 & 0.519 \\
\hline \multicolumn{10}{|l|}{ Random part } \\
\hline & Variance & Std.Dev. & & Variance & Std.Dev. & & Variance & Std.Dev. & \\
\hline Subject & 0.876 & 0.876 & & 0.014 & 0.014 & & 0.000 & 0.000 & \\
\hline Residual & 0.936 & 0.936 & & 0.116 & 0.116 & & 0.000 & 0.000 & \\
\hline \multicolumn{10}{|l|}{ Fit } \\
\hline $\mathrm{AIC}$ & 4.287 .111 & & & 182.060 & & & 135.803 & 4.287 .111 & \\
\hline $\mathrm{BIC}$ & 4.325 .025 & & & 219.974 & & & 173.717 & 4.325 .025 & \\
\hline Residual DF & 221.000 & & & 221.000 & & & 221.000 & 221.000 & \\
\hline Subjects & 58.000 & & & 58.000 & & & 58.000 & 58.000 & \\
\hline
\end{tabular}

Note: Logistic link, optimizer BOBYQA 


\section{Concluding remarks}

In this paper, we study how attention processes to the AOI of an online establishment vary depending on the different purchasing tasks. As our first contribution, we take an integrative theoretical approach considering both the Stimulus-Organism-Approach framework and the Visual Marketing Attention theory. This paper contributes to the analysis of the online shopping experience in an omnichannel environment by exploring cross-task variation in online shoppers' attention patterns using eye-tracking techniques and combining these data (times, fixations and transfers) with declarative measures (feedback from a questionnaire) in an intrasubject experimental design.

Eye tracking metrics are particularly useful for measuring perceptive processes, and they have been used to study cognitive processes (Reutskaja et al., 2011) and attention to in-store (Pieters and Wedel, 2004) and online advertising stimuli (Drèze and Hussherr, 2003; Lee and Ahn, 2012). However, most of this literature does not control the effect of other characteristics of the individual, such as their involvement or experience, which is a second contribution of this paper.

Our analysis shows that, when subjects are simply exploring a website, time-spent and fixation values in all areas of interest are higher, and between-area attention transfers are more numerous. When subjects are evaluating purchase options, they spent more time and fixations are concentrated in the most task-relevant area, i.e., the product area. Subjects' attention patterns when purchasing the selected option are similar to those observed when they are seeking information, although the time-spent values are lower because the task is less complex. Finally, the postpurchase task is associated with low time-spent values and high fixation on the relevant menu; however, attention transfer is more frequent, due to stimuli from other areas. We can state 
that this task is less powerful at retaining attention than the other three. Therefore, during the postpurchase task, which is the one that stimulates the least interest and involvement, subjects are more likely to transfer their attention to task-irrelevant areas (product area and header), which shows that these areas can play an important role at any stage of the shopping process.

Thus, our results also show how data on attention processes can prove useful regarding managing the increasingly complex consumer journey, even in the final stages of a purchasing process (the post purchase stage), when additional stimuli can encourage a new purchase or at least create a more positive brand image. Although the transfer of attention towards adjacent areas is only momentary, it continues to have usefulness potential, as shown in Lindgaard et al. (2006) where 50 milliseconds is sufficiently long for evaluation to occur. After-sale visits to the webpage are an opportunity to focus on new stimuli, as our results show that transfers of attention to other areas are most frequent at this stage. Similarly, the header can continue to help to reinforce brand recognition in after-sale visits to the website. Managers should also concentrate on the product content area when attempting to develop brand image, as this area is the main focus of attention during all tasks.

Category involvement also affects these patterns. Higher involvement increases attention to the product area, thus showing that motivated shoppers process product-related information more thoroughly. No noteworthy variation is observed in relation to ease with online information seeking and with shopping online, possibly because of the homogeneity of the sample in this respect. This finding may indicate a direction for future research.

Regarding future research, as the literature has shown, images and text do not have the same attention-grabbing potential (Liu et al., 2011). We wonder whether these two factors play different roles at different stages in the shopping process and consider it an interesting question 
for future research. Another issue that is not covered by this paper is how attention patterns influence the final purchase choice or other behavioral variables.

As a last suggestion, it might be interesting to explore variation in relation to product-category attributes, such as complexity, and whether they require sensory or nonsensory (Trijp et al., 1996) evaluation. Although our experimental design is not suited to measuring category effects, the observed signs of variation in relation to the degree of product-category interest point to another potentially fruitful line of research. 


\section{References}

Agresti, A., 2003. Categorical data analysis. John Wiley \& Sons.

Ahn, J.H., Bae, Y.S., Ju, J., Oh, W., 2018. Attention Adjustment, Renewal, and Equilibrium Seeking in Online Search: An Eye-Tracking Approach. Journal of Management Information Systems 35, 1218-1250. https://doi.org/10.1080/07421222.2018.1523595

Al-Qeisi, K., Dennis, C., Alamanos, E., Jayawardhena, C., 2014. Website design quality and usage behavior: Unified theory of acceptance and use of technology. Journal of Business Research 67, 2282-2290. https://doi.org/10.1016/j.jbusres.2014.06.016

Badre, A., 2002. Shaping Web usability: interaction design in context. Addison-Wesley Professional.

Bates, D., Maechler, M., Bolker, B., Walker, S., Others, 2014. lme4: Linear mixed-effects models using Eigen and S4. R package version 1, 1-23.

Beck, N., Rygl, D., 2015. Categorization of multiple channel retailing in Multi-, Cross-, and Omni-Channel Retailing for retailers and retailing. Journal of Retailing and Consumer Services 27, 170-178. https://doi.org/10.1016/j.jretconser.2015.08.001

Belanche, D., Flavián, C., Pérez-Rueda, A., 2017. Understanding Interactive Online Advertising: Congruence and Product Involvement in Highly and Lowly Arousing, Skippable Video Ads. Journal of Interactive Marketing 37, 75-88.

https://doi.org/10.1016/j.intmar.2016.06.004

Bernard, B.M., Sheshadri, A., 2004. Preliminary Examination of Global Expectations of Users’ Mental Models for E-Commerce Web Layouts. Usability News 6, 1-9. 
Brasel, S.A., Gips, J., 2008. Breaking Through Fast-Forwarding: Brand Information and Visual Attention. Journal of Marketing 72, 31-48. https://doi.org/10.1509/jmkg.72.6.31

Carey, V.J., Wang, Y.-G., 2001. Mixed-Effects Models in S and S-Plus. Journal of the American Statistical Association 96, 1135-1136. https://doi.org/10.1198/jasa.2001.s411

Cassab, H., MacLachlan, D.L., 2009. A consumer-based view of multi-channel service. Journal of Service Management 20, 52-75. https://doi.org/10.1108/09564230910936850

Castilla, D., Garcia-Palacios, A., Miralles, I., Breton-Lopez, J., Parra, E., Rodriguez-Berges, S., Botella, C., 2016. Effect of Web navigation style in elderly users. Computers in Human Behavior 55, 909-920. https://doi.org/10.1016/j.chb.2015.10.034

Chiou, W.C., Lin, C.C., Perng, C., 2010. A strategic framework for website evaluation based on a review of the literature from 1995-2006. Information and Management 47, 282-290. https://doi.org/10.1016/j.im.2010.06.002

Chocarro, R., Cortinas, M., Elorz, M., 2018. Omnichannel Behaviour. Definitions and Covariables. SSRN series. https://doi.org/10.13140/RG.2.2.13371.52004

Cortiñas, M., Chocarro, R. and Villanueva, A., 2019. Image, Brand and Price Info: do they always matter the same? https://doi.org/https://doi.org/10.1145/3317960.3321616

Dailey, L., 2004. Navigational web atmospherics: Explaining the influence of restrictive navigation cues. Journal of Business Research 57, 795-803. https://doi.org/10.1016/S01482963(02)00364-8

Davenport, T.H., Beck, J.C., 2001. The attention economy: understanding the new currency of business. Harvard Business School Press. 
Dedeke, A.N., 2016. Travel web-site design: Information task-fit, service quality and purchase intention. Tourism Management 54, 541-554.

https://doi.org/10.1016/j.tourman.2016.01.001

Djamasbi, S., Siegel, M., Tullis, T., 2010. Generation Y, web design, and eye tracking. International Journal of Human Computer Studies 68, 307-323.

https://doi.org/10.1016/j.ijhcs.2009.12.006

Drèze, X., Hussherr, F.X., 2003. Internet advertising: Is anybody watching? Journal of Interactive Marketing 17, 8-23. https://doi.org/10.1002/dir.10063

Eroglu, S.A., Machleit, K.A., Davis, L.M., 2001. Atmospherics qualities of online retailing: A conceptual model and implications. Journal of Business Research 54, 177-184. https://doi.org/10.1016/S0148-2963(99)00087-9

Ettis, S.A., 2017. Examining the relationships between online store atmospheric color, flow experience and consumer behavior. Journal of Retailing and Consumer Services 37, 43-55. https://doi.org/10.1016/j.jretconser.2017.03.007

Flavián, C., Gurrea, R., Orús, C., 2010. Effects of visual and textual information in online product presentations: Looking for the best combination in website design. European Journal of Information Systems 19, 668-686. https://doi.org/10.1057/ejis.2010.42

Gehrer, N.A., Schönenberg, M., Duchowski, A.T., Krejtz, K., 2018. Implementing Innovative Gaze Analytic Methods in Clinical Psychology A Study on Eye Movements in Antisocial Violent Offenders. Proceedings of the 2018 ACM Symposium on Eye Tracking Research \& Applications. https://doi.org/10.1145/3204493.3204543 
Gentile, J.R., Roden, A.H., Klein, R.D., 1972. An analysis-of-variance model for the intrasubject replication design. Journal of Applied Behavior Analysis 5, 193-198. https://doi.org/10.1901/jaba.1972.5-193

Hasan, B., 2016. Perceived irritation in online shopping: The impact of website design characteristics. Computers in Human Behavior 54, 224-230.

https://doi.org/10.1016/j.chb.2015.07.056

Hausman, A.V., Siekpe, J.S., 2009. The effect of web interface features on consumer online purchase intentions. Journal of Business Research 62, 5-13. https://doi.org/10.1016/j.jbusres.2008.01.018

Herrando, C., Jimenez-Martinez, J., Hoyos, M.J.M. de, 2018. Surfing or flowing? How to retain e-customers on the internet. Spanish Journal of Marketing - ESIC. https://doi.org/10.1108/SJME-03-2018-006

Holzschlag, M.E., 1998. Web by design: the complete guide. Sybex.

Hong, W., Thong, J.Y.L., Tam, K.Y., 2004. The effects of information format and shopping task on consumers' online shopping behavior: A cognitive fit perspective. Journal of Management Information Systems 21, 149-184.

https://doi.org/10.1080/07421222.2004.11045812

Huang, Y.T., 2018. The female gaze: Content composition and slot position in personalized banner ads, and how they influence visual attention in online shoppers. Computers in Human Behavior 82, 1-15. https://doi.org/10.1016/j.chb.2017.12.038 
Huizingh, E.K.R., 2000. The content and design of web sites: an empirical study. Information \& Management 37, 123-134. https://doi.org/10.1016/S0378-7206(99)00044-0

Katz, M.A., Byrne, M.D., 2003. Effects of scent and breadth on use of site-specific search on e-commerce Web sites. ACM Transactions on Computer-Human Interaction 10, 198-220. https://doi.org/10.1145/937549.937551

Kellogg, R.T., 1980. Is conscious attention necessary for long-term storage? Journal of Experimental Psychology: Human Learning \& Memory 6, 379-390.

https://doi.org/10.1037/0278-7393.6.4.379

Kotler, P., 1973. Atmospherics as a marketing tool. Journal of Retailing 49, 48-65. https://doi.org/10.1016/j.obhdp.2011.03.002

Lee, J., Ahn, J.-H., 2012. Attention to Banner Ads and Their Effectiveness: An Eye-Tracking Approach. International Journal of Electronic Commerce 17, 119-137.

https://doi.org/10.2753/JEC1086-4415170105

Lemon, K.N., Verhoef, P.C., 2016. Understanding Customer Experience Throughout the Customer Journey. Journal of Marketing 80, 69-96. https://doi.org/10.1509/jm.15.0420

Leuthold, S., Schmutz, P., Bargas-Avila, J.A., Tuch, A.N., Opwis, K., 2011. Vertical versus dynamic menus on the world wide web: Eye tracking study measuring the influence of menu design and task complexity on user performance and subjective preference. Computers in Human Behavior 27, 459-472. https://doi.org/10.1016/j.chb.2010.09.009 
Lin, J., Yan, Y., Chen, S., Luo, X.(., 2017. Understanding the impact of social commerce website technical features on repurchase intention: a Chinese Guanxi perspective. Journal of Electronic Commerce Research 18, 225-244.

Lindgaard, G., Fernandes, G., Dudek, C., Browñ, J., 2006. Attention web designers: You have 50 milliseconds to make a good first impression! Behaviour and Information Technology 25, 115-126. https://doi.org/10.1080/01449290500330448

Liu, H.-C., Lai, M.-L., Chuang, H.-H., 2011. Using eye-tracking technology to investigate the redundant effect of multimedia web pages on viewers' cognitive processes. Computers in Human Behavior 27, 2410-2417. https://doi.org/10.1016/j.chb.2011.06.012

Luqman, A., Cao, X., Ali, A., Masood, A., Yu, L., 2017. Empirical investigation of Facebook discontinues usage intentions based on SOR paradigm. Computers in Human Behavior 70, 544555. https://doi.org/10.1016/j.chb.2017.01.020

Manippa, V., Laan, L.N. van der, Brancucci, A., Smeets, P.A.M., 2019. Health body priming and food choice: An eye tracking study. Food Quality and Preference 72, 116-125. https://doi.org/10.1016/j.foodqual.2018.10.006

Marketing Science Institute, 2018. Research priorities 2018-2020.

Mehrabian, A., Russell, J.A., 1974. An approach to environmental psychology.

Meyer, C., Schwager, A., 2007. Understanding Customer Experience. Harvard Business Review 85, 116-124. https://doi.org/10.1108/00242539410067746 
Mitra, K., Reiss, M.C., Capella, L.M., 1999. An examination of perceived risk, information search and behavioral intentions in search, experience and credence services. Journal of Services Marketing 13, 208-228. https://doi.org/10.1108/08876049910273763

Näätänen, R., 2018. Attention and brain function. Routledge.

Neslin, S.A., Grewal, D., Leghorn, R., Shankar, V., Teerling, M.L., Thomas, J.S., Verhoef, P.C., 2006. Challenges and opportunities in multichannel customer management. Journal of Service Research 9, 95-112. https://doi.org/10.1177/1094670506293559

ONTSI, 2018. Estudio sobre Comercio Electrónico B2C 2017. Observatorio Nacional de las Telecomunicaciones y la SI.

Pashler, H., 2016. Attention. Psychology Press.

Pieters, R., Wedel, M., 2004. Attention Capture and Transfer in Advertising: Brand, Pictorial, and Text-Size Effects. Journal of Marketing 68, 36-50.

https://doi.org/10.1509/jmkg.68.2.36.27794

Puccinelli, N.M., Goodstein, R.C., Grewal, D., Price, R., Raghubir, P., Stewart, D., 2009. Customer Experience Management in Retailing: Understanding the Buying Process. Journal of Retailing 85, 15-30. https://doi.org/10.1016/j.jretai.2008.11.003

Rayner, K., Rotello, C.M., Stewart, A.J., Keir, J., Duffy, S.A., 2001. Integrating text and pictorial information: Eye movements when looking at print advertisements. Journal of Experimental Psychology: Applied 7, 219-226. https://doi.org/10.1037/1076-898X.7.3.219 
Reutskaja, E., Nagel, R., Camerer, C.F., Rangel, A., 2011. Search dynamics in consumer choice under time pressure: An eye-tracking study. American Economic Review 101, 900-926. https://doi.org/10.1257/aer.101.2.900

Richard, M.O., 2005. Modeling the impact of internet atmospherics on surfer behavior. Journal of Business Research 58, 1632-1642. https://doi.org/10.1016/j.jbusres.2004.07.009

Rossiter, J.R., Donovan, R.J., 1982. Store Atmosphere: An Environmental Psychology Approach. Journal of Retailing 58, 34. https://doi.org/Article

Rowley, J., 2000. Product search in e-shopping: a review and research propositions. Journal of Consumer Marketing 17, 20-35.

Samant, S.S., Seo, H.S., 2016. Effects of label understanding level on consumers' visual attention toward sustainability and process-related label claims found on chicken meat products. Food Quality and Preference 50,48-56. https://doi.org/10.1016/j.foodqual.2016.01.002

Sandage, C.H., 1946. Advertising: Theory and Practice. Richard D. Irwing.

Shi, S.W., Wedel, M., Pieters, R., 2013. Information Acquisition During Online Decision Making: A Model-Based Exploration Using Eye-Tracking Data. Management Science 59, 10091026. https://doi.org/10.1287/mnsc.1120.1625

Sopadjieva, E., Dholakia, U., Benjamin, B., 2017. A study of 46,000 shoppers shows that omnichannel retailing works. Harvard Business Review 3.

Statista, 2019. Annual retail e-commerce sales growth worldwide from 2014 to 2021. 
Trijp, H.C.M.V., Hoyer, W.D., Inman, J.J., 1996. Why Switch? Product Category: Level Explanations for True Variety-Seeking Behavior. Journal of Marketing Research 33, 281-292. https://doi.org/10.2307/3152125

Turley, L.W., Milliman, R.E., 2000. Atmospheric Effects on Shopping Behavior. Journal of Business Research 49, 193-211. https://doi.org/10.1016/S0148-2963(99)00010-7

Van Duyne, D.K., Landay, J.A., Hong, J.I., 2003. The design of sites: patterns, principles, and processes for crafting a customer-centered Web experience. Addison-Wesley.

Velásquez, J.D., 2013. Combining eye-tracking technologies with web usage mining for identifying Website Keyobjects. Engineering Applications of Artificial Intelligence 26, 14691478. https://doi.org/10.1016/j.engappai.2013.01.003

Verhoef, P.C., Kannan, P.K., Inman, J.J., 2015. From Multi-Channel Retailing to OmniChannel Retailing. Introduction to the Special Issue on Multi-Channel Retailing. Journal of Retailing 91, 174-181. https://doi.org/10.1016/j.jretai.2015.02.005

Verhoef, P.C., Neslin, S.A., Vroomen, B., 2007. Multichannel customer management: Understanding the research-shopper phenomenon. International Journal of Research in Marketing 24, 129-148. https://doi.org/10.1016/j.ijresmar.2006.11.002

Wang, Q., Yang, S., Liu, M., Cao, Z., Ma, Q., 2014. An eye-tracking study of website complexity from cognitive load perspective. Decision Support Systems 62, 1-10.

https://doi.org/10.1016/j.dss.2014.02.007 
Wang, W., Lee, K., Murray, D., 2017. A global generic architecture for the future Internet of Things. Service Oriented Computing and Applications 11, 329-344.

https://doi.org/10.1007/s11761-017-0213-1

Wedel, M., 2015. Attention research in marketing: A review of eye-tracking studies. The handbook of attention 569-588.

Wedel, M., Pieters, R., 2008. A Review of Eye-Tracking Research in Marketing, in: Review of Marketing Research. pp. 123-147.

Wedel, M., Pieters, R., 2000. Eye Fixations on Advertisements and Memory for Brands: A Model and Findings. Marketing Science 19, 297-312.

https://doi.org/10.1287/mksc.19.4.297.11794

Wolfe, J.M., 1998. Visual search, in: Pashler, H. (Ed.), Atttention. Psychology press.

Wood, W., Quinn, J.M., Kashy, D.A., 2002. Habits in everyday life: Thought, emotion, and action. Journal of Personality and Social Psychology 83, 1281-1297.

https://doi.org/10.1037/0022-3514.83.6.1281

Yandandul, Chaitra and Paryani, Sachin and Le, Madison and Jain, E., 2018. How many words is a picture worth? Attention allocation on thumbnails versus title text regions. ETRA 2018 4. https://doi.org/10.1145/3204493.3204571

Yoo, C.Y., Kim, K., Stout, P.A., 2004. Assessing the Effects of Animation in Online Banner Advertising. Journal of Interactive Advertising 4, 49-60.

https://doi.org/10.1080/15252019.2004.10722087 
Yu, B.M., Roh, S.Z., 2002. The effects of menu design on information-seeking performance and user's attitude on the world wide web. Journal of the American Society for Information Science and Technology 53, 923-933. https://doi.org/10.1002/asi.10117

Zaichkowsky, J.L., 1985. Measuring the Involvement Construct. Journal of Consumer Research 12, 341-352. https://doi.org/10.1086/208520 


\section{Annex 1. Websites}

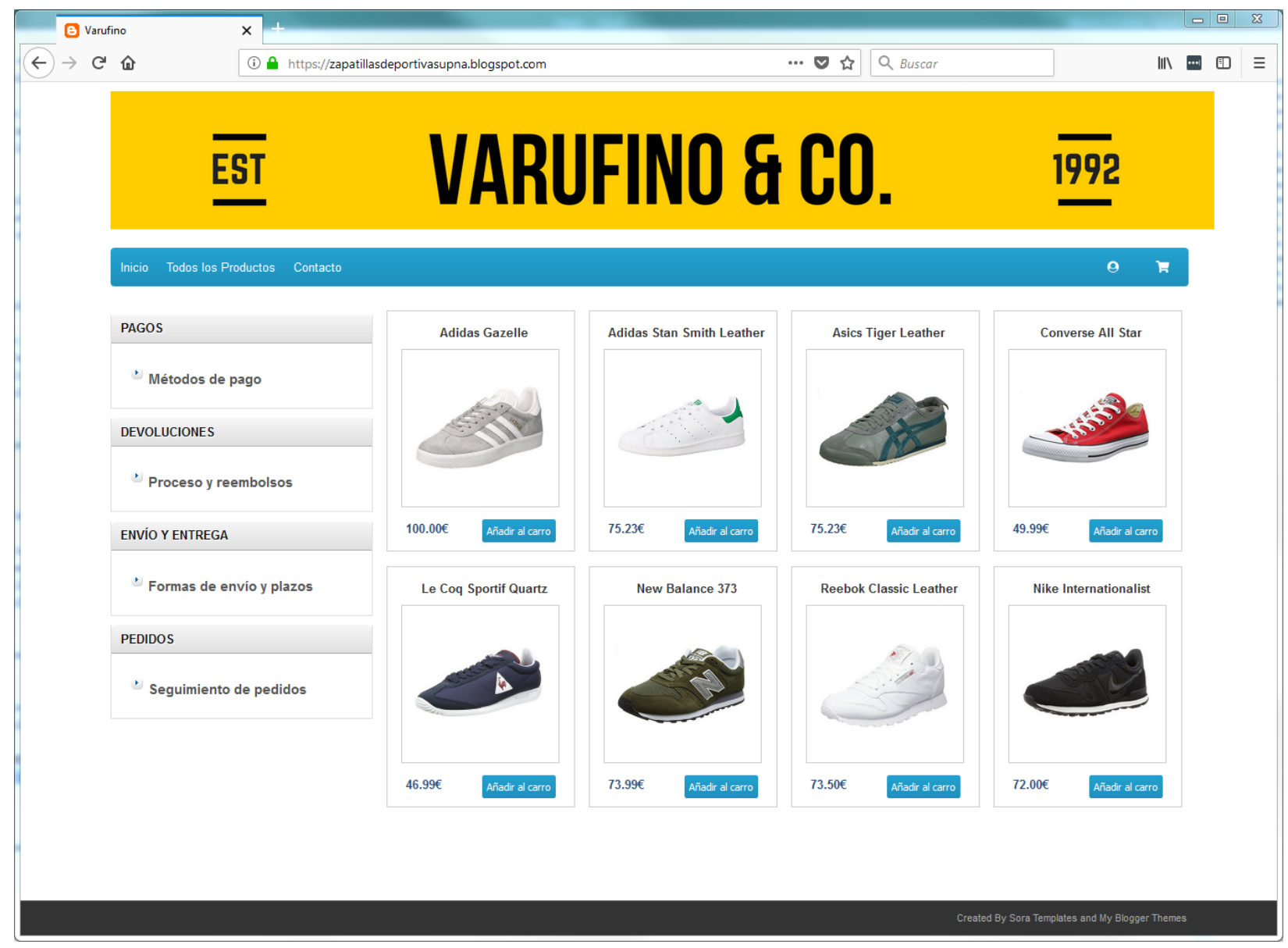




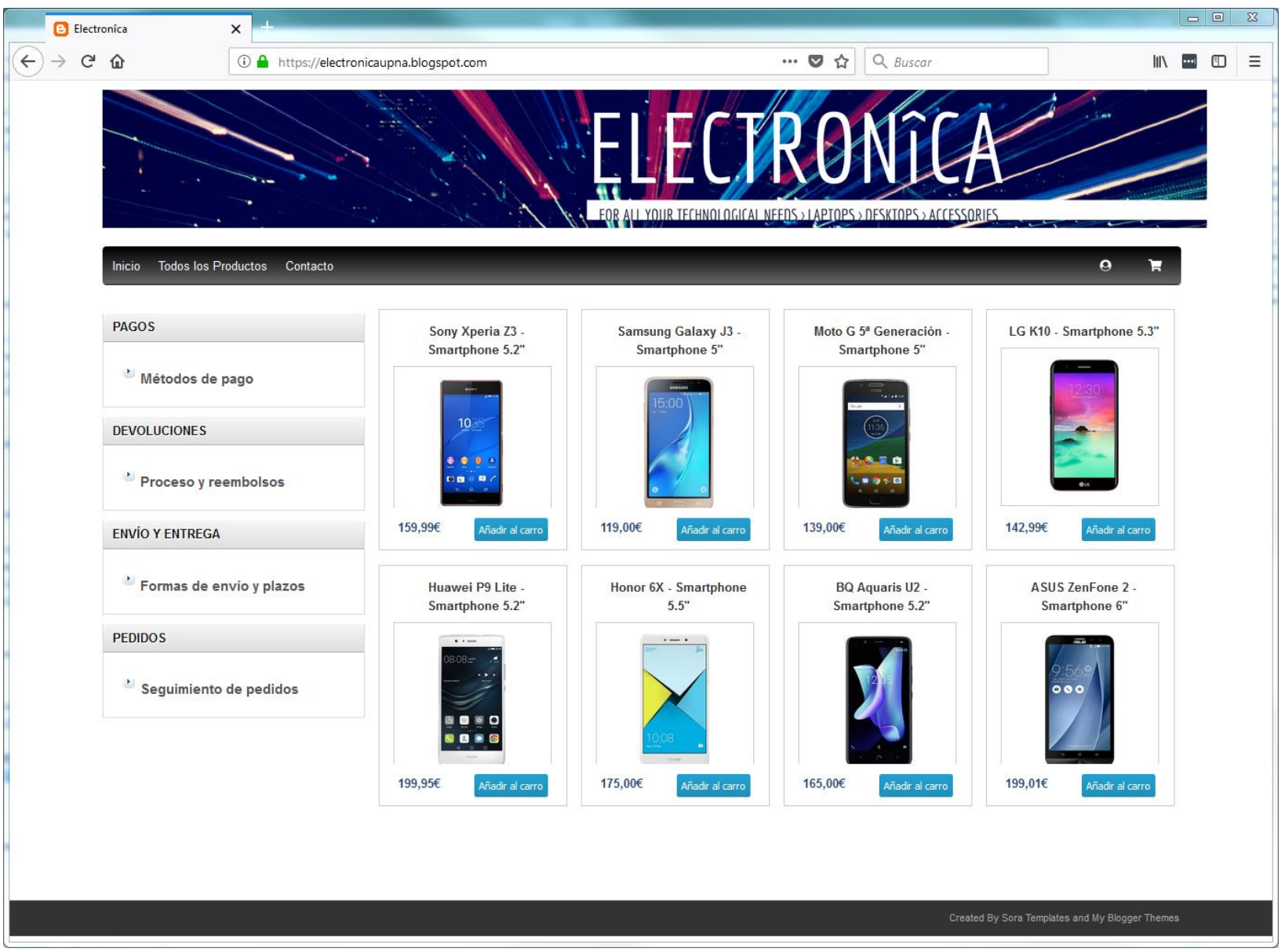




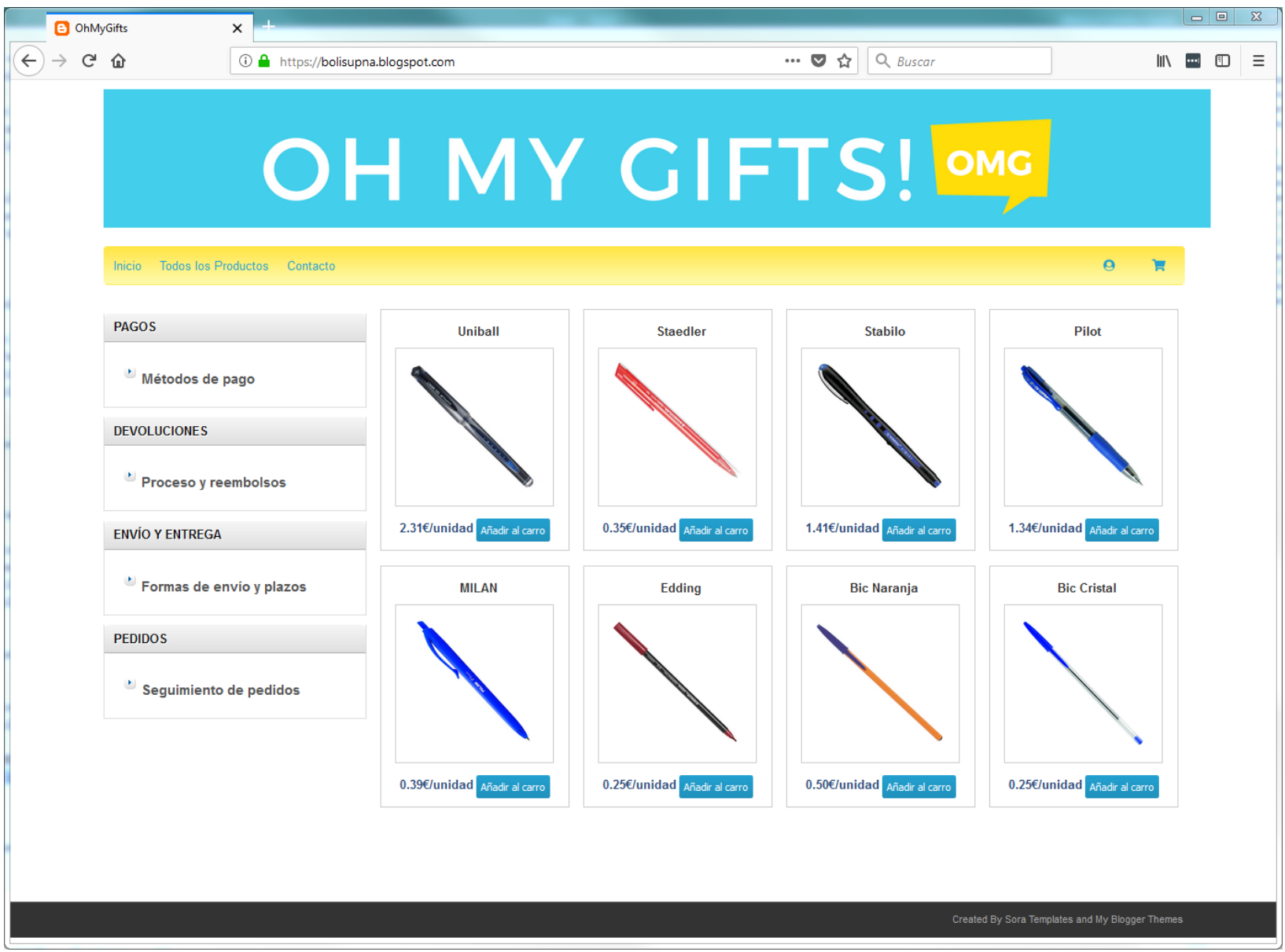




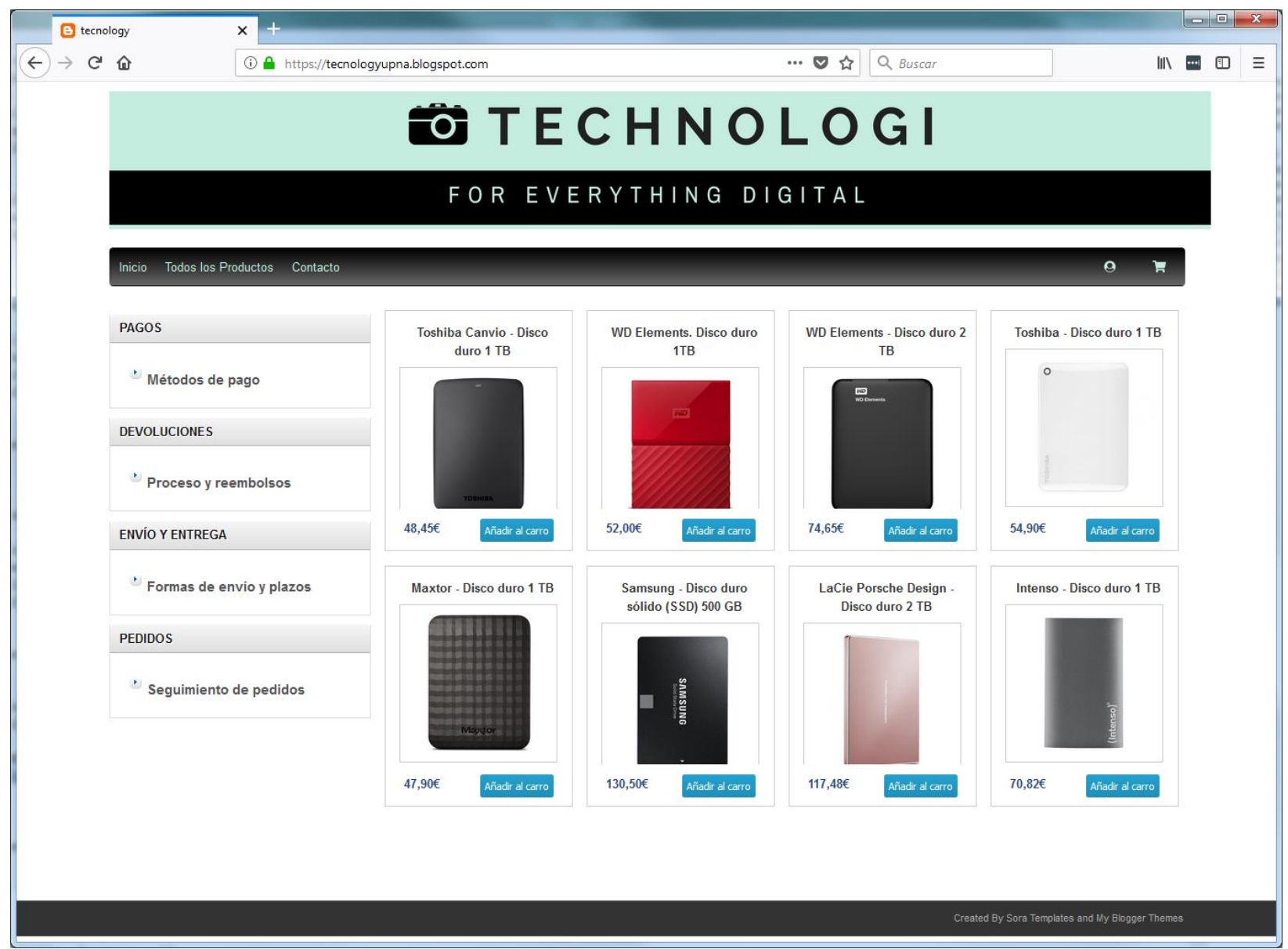




\section{Annex 2. Questionnaire}

\section{For each of the four categories (sports shoes, mobile phones, all-point pens, hard disks)}

Q1. In what follows, we will be talking about category X.

Have you ever bought anything from category X? Yes / No / Don't know / Don't remember

Q2. How often do you buy X? (different interval scale for each category)

Q3. Have you ever bought a/some X? Yes / No / Don't know / Don't remember

Q4. How often do you go online to buy X? Never (0) - Always (10)

Q5. Task presentation: Next, we are going to show you an online X store. Randomly present one of the following tasks:

- TASK 1: We would like you to focus on the appeal of the web page. When you click on the link:

1. Look at the page and consider how much it appeals to you.

2. Once you have formed an opinion, click on any link to return to the questionnaire and answer the questions How appealing do you find this web page? Not at all appealing (1) Very appealing (7)

- $\quad$ TASK 2: We would like you to visit the store to select the model that most appeals to you based on the information you find on screen. When you click on the link:

1. Select the product you would be most likely to buy if you had to choose from the options presented 
2. Add it to your cart. Please select the chosen model or models. (different options for each category)

- TASK 3: We would like you to visit the store to purchase a specific model. When you click on the link, you are required to purchase model "Z", take all the time you need:

1. Please visit the store and locate the model "Z" (different models for each category)

2. Add it to your cart. How difficult did you find this task? Extremely difficult (1) - Extremely easy (7)

- TASK 4: You are required to check the status of an order placed by someone else a week ago.

1. Please visit the store and look to see where you think you might find the information you require.

2. Click on what you consider to be the best link for finding the information you require. How difficult did you find this task? Extremely difficult (1) - Extremely easy (7)

Q6. Indicate your level of agreement or disagreement with the following statements:

- My knowledge of X is very good Strongly disagree (1) - Strongly agree (7)

- It is important for me to make the right choice when shopping for X Strongly disagree (1) Strongly agree (7)

- I find shopping for X interesting Strongly disagree (1) - Strongly agree (7)

Q7. When shopping for X online, how do you rate the following in terms of importance?

- $\quad$ Price Very low (1) - Very high (7)

- $\quad$ Brand Very low (1) - Very high (7)

- $\quad$ Payment modes Very low (1) - Very high (7) 
- $\quad$ Returns and Money Back terms Very low (1) - Very high (7)

- $\quad$ Delivery modes and times Very low (1) - Very high (7)

- $\quad$ Order Tracking 1 Very low (1) - Very high (7)

\section{After completing all four categories:}

Q8. On a scale of 0 to 10 , how would you rate your degree of ease with seeking information through the Internet? Extremely low (0) - Extremely high (10)

Q9. On a scale of 0 to 10 , how would you rate your degree of ease with shopping on the Internet? Extremely low (0) - Extremely high (10)

Q10. Sex Male / Female

Q11. Year of birth

Q12. Level of education attained. No formal education credential / Primary / Secondary / Bachelor's degree / Master's degree / PhD

Q13. Main occupation. If more than one, please indicate the one you consider most relevant. Student / Retired / Homemaker / Unemployed / Employed / Self-employed 


\section{Annex 3. Heat Maps.}

\section{Aggregated Fixations by task. Other Stores}

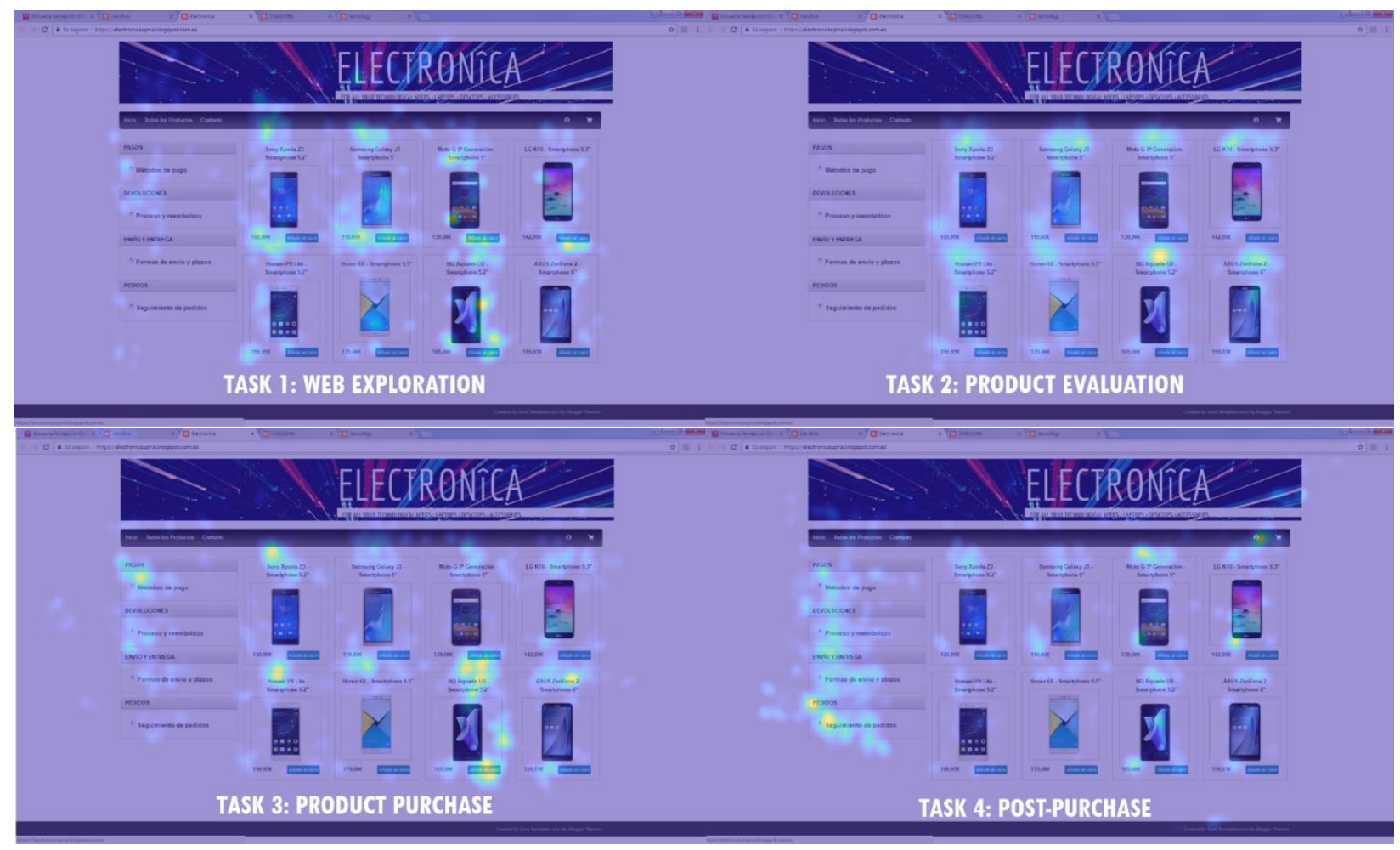

Figure A31. Heat Maps. Aggregated Fixations by task. Mobile Store. 


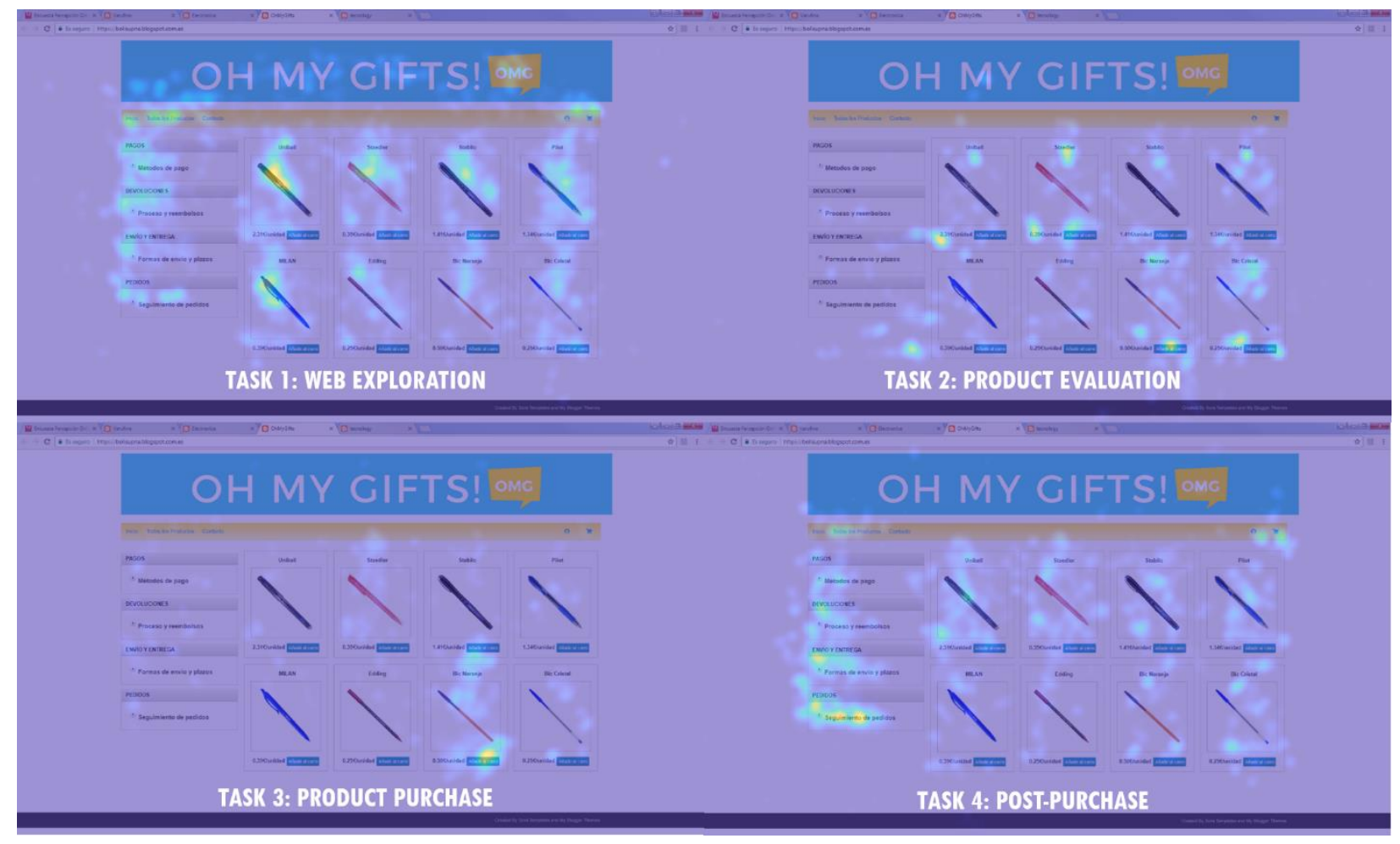

Figure A32. Heat Maps. Aggregated Fixations by task. Ball-point pens Store. 


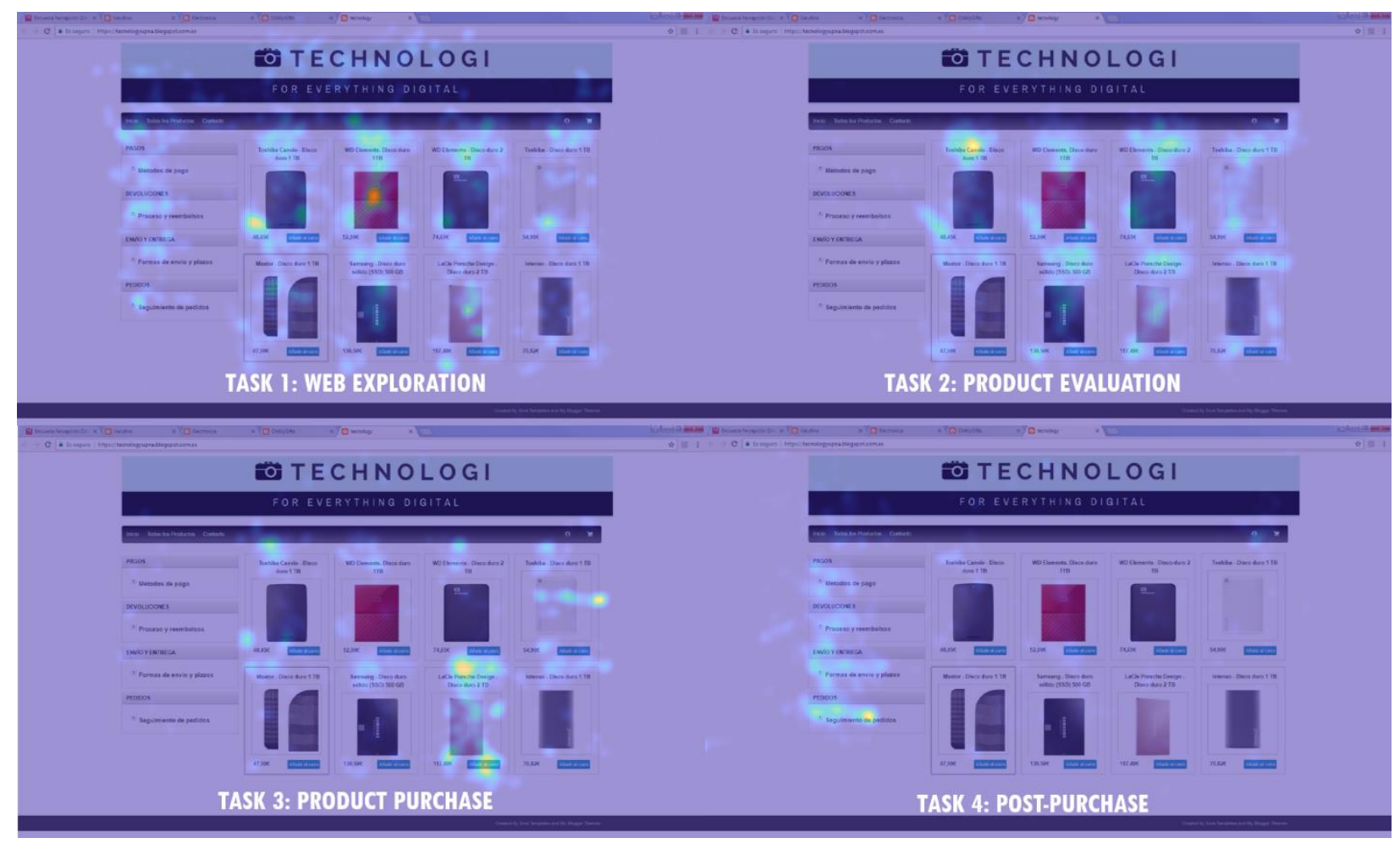

Figure A33. Heat Maps. Aggregated Fixations by task. Hard Disks Store. 